Article

\title{
Testing Western Media Icons Influence on Arab Women's Body Size and Shape Ideals: An Experimental Approach
}

\author{
Salma M. Khaled ${ }^{1, *(1)}$, Bethany Shockley ${ }^{1}$, Yara Qutteina ${ }^{2}$ (D), Linda Kimmel ${ }^{3}$ and Kien T. Le ${ }^{1}$ \\ 1 Social and Economic Survey Research Institute, Qatar University, 2713 Doha, Qatar; \\ bethanynesbit@gmail.com (B.S.); kienle@qu.edu.qa (K.T.L.) \\ 2 KU Leuven, Parkstraat 45, Leuven 3000, Belgium; yara.qu@gmail.com \\ 3 Institute for Social Research, University of Michigan, Ann Arbor, MI 48106-1248, USA; lkimmel@umich.edu \\ * Correspondence: skhaled@qu.edu.qa; Tel.: +974-4403-5754
}

Received: 5 August 2018; Accepted: 26 August 2018; Published: 27 August 2018

check for updates

\begin{abstract}
Western media globalization is implicated in the spread of the thin body ideal to traditional societies. Qatar-a small conservative Middle-Eastern country-has recently witnessed rapid Westernization, but the influence of Western media icons on women's body image dissatisfaction has rarely been studied here. A 2 (celebrity or model) $\times 3$ (thin, average, or heavy) plus a control condition between-subject experiment tested the primary hypothesis that exposure to images of thin Western models or celebrities promotes a thinner body ideal compared to neutral images. A sample of young women $(n=1145)$ was randomly assigned to experimental images as part of an online survey. After exposure to images, participants rated their current and desired body size and shape, reported celebrity liking, and evaluated their favorite celebrity's body. We found little support for the desire of thinness. Viewing thin- and average-sized celebrities was significantly associated with desiring a heavier and a thinner look (respectively) among those favoring thin celebrities. Images of thin models induced the desire for a curvaceous body figure with hips especially among those favoring celebrities with hips. The findings highlight important nuances in the influence of Western media icons on body image among women in a non-Western culture.
\end{abstract}

Keywords: body image dissatisfaction; experiment; body size; body shape; Arab culture; media; celebrities; models

\section{Introduction}

Body image dissatisfaction (BID) is the discrepancy between one's current and ideal body image. Although not necessarily pathological (Cooper and Fairburn 1993), BID is characterized by negative body evaluation and desire for change in weight and/or shape (Grogan 2006); it is considered a susceptibility marker to disordered eating behaviors, eating disorders, low self-esteem, depression, weight gain, and obesity (Brechan and Kvalem 2015; McLean 2013). Findings from studies in Western countries strongly suggest that exposure to thin media-images of thin female models and media icons-is associated with higher levels of BID among women (Grabe et al. 2008; Groesz et al. 2002; Levine and Murnen 2009). The globalization of Western media has been implicated in a shift towards the thin body ideal and BID in non-Western societies (McCabe et al. 2012; Omori et al. 2016; Swami et al. 2010). However, it is unclear how cultural ideals and sociocultural factors may counteract the internalization of the thin-body ideal, hereafter called the desire for thinness. Additionally, little is known about how body shape preferences, not just desire for thinness in size, may also be affected by media icons among women in Western and non-Western societies. 
Qatar is a conservative Muslim country in the Arabian Peninsula that has witnessed remarkable rates of economic growth, Westernization, and modernization over the past decade (Babar 2015). These rapid changes have largely influenced the country's traditional dietary choices and nomadic lifestyle. Today, Qatar's population has some of the highest rates of obesity and diabetes in the world (Ali et al. 2014). Fears of obesity and cultural stereotyping of obese individuals are on the rise especially among women in this part of the world (Musaiger 2015). As such women may be more vulnerable than men to BID due to traditional gender roles and expectations of femininity and beauty. In addition, recent studies show high levels of social media use among this segment of the population, especially Instagram and Snapchat, as well as Twitter and Facebook to a lesser extent (Dennis et al. 2016). These factors may push women to prefer thinness over traditional societal ideals of heavier body size and plumper body shape (Nasser 1986).

In the current study, we examined the acute effects of exposure to thin, average-sized, and heavy-sized images of Western celebrities and models compared to neutral images on the desire for change in body size and shape in a large probability sample of predominantly young Arab women living in Qatar. The study adds to the small body of experimental research on the effects of celebrity images on desire for change in body size and shape ideals using an online platform, with potentially important implications for the role of Western media icons on body ideals among young women in the Arab world.

\section{Literature Review}

\subsection{Western Thin Media}

In Western societies, evidence from experimental studies supports a causal relationship between exposure to thin media and BID among women (Dittmar et al. 2009; Grabe et al. 2008; Groesz et al. 2002; Irving 1990; Levine and Murnen 2009). One study meta-analyzed results from 25 experimental studies and found participants were more dissatisfied with their bodies after viewing thin-sized models than after viewing average-sized models, plus-sized models, or inanimate objects (Groesz et al. 2002).

Exposure to thin media has been linked to BID through stronger internalization of the thin-body ideal (Chang et al. 2013; Grabe et al. 2008). Women who internalized the thin beauty ideal were more affected by the sight of thin models than those who saw the same images, but did not internalize the thin ideal (Groesz et al. 2002). Thus, how women process the images they view is important (Brown and Dittmar 2005; Dittmar 2009; Dittmar and Howard 2004; Halliwell and Dittmar 2005; Thompson and Stice 2001; Tiggemann et al. 2009).

Social comparison theory (Festinger 1954), suggests that BID is the result of a comparison with fashion models and media icons on a relevant dimension such as appearance (Cattarin et al. 2000; Levine and Murnen 2009; Tiggemann and McGill 2004; Want 2009). When women who internalized thin body ideals were exposed to ads of thin models they compared themselves to these models, increasing BID (Tiggemann and Polivy 2010). In contrast, those exposed to average-sized and over-sized models were more satisfied with their bodies (Groesz et al. 2002; Irving 1990), suggesting social comparison may be constructive if models are not thin.

In summary, it appears that the effects of media on women's BID are moderated by individual differences in women's internalization of the thin ideal and a tendency to make social comparisons with thin media images (Dittmar and Howard 2004). Most studies assessing thin media's impact on BID focus on body size or body weight ideals, while a simultaneous assessment of body shape, a concept determined by regional differences in fat distribution (Vague 1956), is often lacking. This constitutes a major limitation of the present literature because body size and body shape are distinct, yet overlapping variables (Singh 1994). As such BID could be due not only to body size, but also to dissatisfaction with body shape (Singh 1994). 


\subsection{Thin Media in Arab Societies}

We identified no experimental studies that examined the direct effects of thin media exposure on Arab women's body ideals. Moreover, all of the available evidence was correlational and based on studies with small convenience samples. One of the earliest studies conducted in Egypt reported an association between body weight dissatisfaction and frequency of viewing television and fashion magazines (Nasser 1986). A study in the United Arab Emirates reported that women with high scores on a measure of disordered eating were more likely to watch Western television programs (Eapen et al. 2006). In Jordan, women, who scored high on a measure of emotional eating were more likely to report media pressure to modify their appearance (Madanat et al. 2007). Another study in Jordan reported significant associations between high BID levels and exposure to media messages that promote unhealthy weight loss behaviors among adolescent school girls (Mousa et al. 2010). While these studies show positive associations between exposure to media, BID, and eating behaviors, it is unclear what aspects of Western media images precipitate these effects.

\subsection{Image Type}

Although the available Western literature has focused primarily on the impact of exposure to fashion models, favored thin female celebrities (models or not) may invoke stronger unrealistic social comparisons that contribute to higher BID and desire for thinness among women than non-celebrity models (Harrison 1997; Shorter et al. 2008; Swami et al. 2011a). However, experimental evidence supporting the influence of celebrities on women's body ideals remains scarce. One of the first studies to do so was a recent experiment that assessed the impact of three image types (celebrity, peer, travel) on body image in Western country setting (Brown and Tiggemann 2016). The study found that acute exposure to thin female celebrity images had an immediate negative effect on women's body satisfaction when compared to travel (neutral) images (Brown and Tiggemann 2016). Rather unexpectedly, exposure to images of thin celebrities had similar negative effects on BID as exposure to images of thin and attractive, but unknown peers. This study also showed that the effect of celebrity images on BID was moderated by celebrity worship with the greatest negative effect observed for those who were high on celebrity worship and viewed celebrity images than those who were low on celebrity worship or those who viewed other types of images (Brown and Tiggemann 2016). It is uncertain whether these results would apply to contexts where sociocultural ideals of beauty are different. Furthermore, it may be important to disentangle the effects of favored celebrities' body shape from body size by estimating their independent impact on body ideals.

\subsection{Culture}

Cultural influences on body ideals have been well documented. Preference for body sizes, body shapes (curvature or lack thereof), and related features (including hips, breasts, etc.) also vary across cultures (Furnham and Alibhai 1983; Furnham and Baguma 1994). In turn, women's ideals for body size and shape are typically influenced by sociocultural factors including perceived preferences by societal norms (Singh and Young 1995). In Western societies, a shift in media portrayal of the ideal female body towards a thinner and a less curvy figure has been documented (Garner et al. 1980).

In the context of Arab culture, many studies attribute women's rise in BID to shifts in body size ideals toward thinness (Madanat et al. 2007; Madanat et al. 2010; Musaiger 2015; Nasser 1988) in a culture where historically the preference for heavier and plumper sizes and shapes for women has been widely reported (Nasser 1986, 1988, 1997). Findings from these studies imply that thin Western media may promote BID in Arab women who subscribe to Western ideals of beauty (including thinness) or those who do not conform to the traditional beauty ideals of Arab culture in general. However, we found no studies that directly measured perception of ideal body shape, but only perception of current versus ideal body size (Ford et al. 1990). Thus, it is difficult to ascertain whether the presumed shift towards thinness is due to shifts in body size or body shape ideals or both. 
Culture may also be an important moderator of the impact of thin media effects on BID in women from non-Western societies (Swami et al. 2011b). An early study reported a higher proportion of Arab women in Britain had abnormal scores on a measure of disordered eating than women in Egypt and attributed this to differences in levels of Westernization (Nasser 1986). A more recent study found that although Jordanian female college students spent more time with media than American students, they reported significantly less internalization of appearance ideals (Baptista 2011). A study conducted in the U.S. reported Muslim women wearing traditional clothing were less likely than those wearing Western clothing to conform to thin ideals (Dunkel et al. 2010). These results suggest there may be cultural factors affecting internalization of the media including Westernization (Nasser 1986) and traditional style of dress (Dunkel et al. 2010). Other studies showed that strength of religious faith may also be a protective factor (Boyatzis and Quinlan 2008; Mahoney et al. 2005).

\section{Current Study}

The aim of the present study was to examine the effects of acute exposure to thin-, average- or heavy-sized images of Western celebrities and non-celebrity fashion models compared to neutral (control) images on women's desire for a change in body size and shape. Our primary hypothesis was that respondents exposed to images of thin celebrities or thin models would be more likely to desire thinness compared to those who viewed neutral images. We also hypothesized that the effect of the treatment would be moderated by favorite celebrity's body size. In particular, participants who already favored thin celebrities and were exposed to images of thin celebrities would be more likely to desire thinness compared to those who viewed neutral images. Similar, but weaker effects were hypothesized for those who favored thin celebrities and were exposed to thin models. Meanwhile, we predicted that favoring average- or heavy-sized celebrities would be negatively associated with the desire for thinness irrespective of the type of images received. Finally, we tested moderation effects between favorite celebrities' body shapes and the treatments on participants' desire for change in body shape. This part of the study was exploratory due to the scarcity of experimental studies published on these effects.

To our knowledge, this is the first study in the region to explore effects of exposure to images of media icons using an experimental design administered through an online platform. Additionally, our study is potentially the first of its kind to assess how perception of favorite media celebrities' body size and shape influence processing of images of other media icons (celebrities, models) of varying body size (thin, average, heavy) and their potential effects on participants' own body size and shape ideals.

\section{Methods}

\subsection{Language \& Translation Procedures}

All measures and instructions used in the study were translated from English to Arabic by the first author who is bilingual. Two other bilingual research team members verified the translation and all three team members reached a consensus on any disagreements.

\subsection{Pilot and Qualitative Interviews}

All measures, images, instructions, and procedures were tested in a pilot study $(n=120)$. During this pilot, an open-ended question that asked participants to name their three most favorite Western celebrities was used to derive a list of the most popular celebrities. The most named celebrities were sorted into thin-, average-, and heavy-sized categories based on consensus among research team members of their perceived body size. Following the pilot, one-on-one qualitative (cognitive) interviews with twenty female university students were conducted to verify the classification of these celebrities into the respective three body size categories. The students' familiarity with images of these celebrities was also visually tested in addition to simple name recognition. Neutral images (control condition) were also tested; images that evoked either positive or negative associations were 
not used in the experiment. The face validity and conceptual equivalence of the English-to-Arabic translation of the measures and instructions were also tested during these interviews.

\subsection{Overview of Study Procedures}

First, we obtained ethics approval from the University's Institutional Review Board (QU-IRB 552-E/16) to conduct all components of the study. Following the pilot and qualitative interviews, the experimental images (treatment or control) were administered as part of a 30-min online survey to respondents via Qualtrics. Data was collected from November 2016 through February 2017. Respondent were given the choice to complete the online survey in either Arabic or English and could view the survey and images on their laptop computers, mobile phones, or tablets. First, respondents were administered the experimental images and were asked to confirm having seen each image before advancing to the next one. No time restrictions were applied for viewing the images, but respondents could not view or edit their answers after viewing the experimental images. Second, participants were then asked to rate their current and desired body size and shape. Third, participants were asked about their recognition and liking of each celebrity. Finally, participants were asked to select their favorite celebrity from the list and to evaluate their favorite celebrity's body size and shape.

\subsubsection{Experimental Design}

A 2 (celebrity or model) $\times 3$ (thin, average, or heavy) plus a control (neutral) condition between-subjects design was used to investigate the effects of three image types (celebrity, model, neutral) on BID in body size and body shape. The Halton sequence was used to randomly assign respondents to the three experimental groups. This approach was favored over the random number method as it has achieved a higher level of precision in Monte Carlo simulations (Morokoff and Caflisch 1995). For experimental balance verification see Table 1.

Table 1. Percentages for Manipulation Check.

\begin{tabular}{|c|c|c|c|c|c|c|c|c|c|c|}
\hline & & & & & & ment Gr & aps & & & \\
\hline & $\begin{array}{c}\text { Total } \\
\text { Sample } \\
\%(N)\end{array}$ & $\begin{array}{c}\text { Thin } \\
\text { Model } \\
\%\end{array}$ & $\begin{array}{c}\text { Thin } \\
\text { Celebrity } \\
\%\end{array}$ & $\begin{array}{c}\text { Normal } \\
\text { Model } \\
\%\end{array}$ & $\begin{array}{c}\text { Normal } \\
\text { Celebrity } \\
\%\end{array}$ & $\begin{array}{c}\text { Heavy } \\
\text { Model } \\
\%\end{array}$ & $\begin{array}{c}\text { Heavy } \\
\text { Celebrity } \\
\%\end{array}$ & $\begin{array}{c}\text { Neutral } \\
\%\end{array}$ & $\begin{array}{c}\text { Total } \\
\%\end{array}$ & $\begin{array}{c}\mathrm{Chi}^{2} \\
\text { (p-Value) }\end{array}$ \\
\hline $\begin{array}{c}\text { Nationality } \\
\text { Non-Qatari } \\
\text { Qatari }\end{array}$ & $\begin{array}{l}37.0(520) \\
63.0(886)\end{array}$ & $\begin{array}{l}14.6 \\
17.7\end{array}$ & $\begin{array}{l}12.8 \\
15.3\end{array}$ & $\begin{array}{l}13.5 \\
13.0\end{array}$ & $\begin{array}{l}13.9 \\
12.4\end{array}$ & $\begin{array}{l}13.8 \\
15.3\end{array}$ & $\begin{array}{l}15.3 \\
13.1\end{array}$ & $\begin{array}{l}16.1 \\
13.2\end{array}$ & $\begin{array}{l}100 \\
100\end{array}$ & $\begin{array}{c}3.722 \\
(0.714)\end{array}$ \\
\hline $\begin{array}{l}\text { Language } \\
\text { Arabic } \\
\text { English }\end{array}$ & $\begin{array}{l}77.0(793) \\
23.0(238)\end{array}$ & $\begin{array}{l}15.4 \\
16.4\end{array}$ & $\begin{array}{l}13.9 \\
16.0\end{array}$ & $\begin{array}{l}13.6 \\
13.0\end{array}$ & $\begin{array}{l}13.1 \\
14.7\end{array}$ & $\begin{array}{l}13.8 \\
16.8\end{array}$ & $\begin{array}{l}15.0 \\
10.0\end{array}$ & $\begin{array}{l}15.2 \\
13.1\end{array}$ & $\begin{array}{l}100 \\
100\end{array}$ & $\begin{array}{l}6.073 \\
(0.415)\end{array}$ \\
\hline $\begin{array}{l}\text { Marriage Status } \\
\text { Single } \\
\text { Married }\end{array}$ & $\begin{array}{l}80.0(786) \\
20.0(194)\end{array}$ & $\begin{array}{l}15.8 \\
13.4\end{array}$ & $\begin{array}{l}14.6 \\
13.4\end{array}$ & $\begin{array}{l}12.7 \\
17.5\end{array}$ & $\begin{array}{l}13.9 \\
12.4\end{array}$ & $\begin{array}{l}15.5 \\
11.9\end{array}$ & $\begin{array}{l}13.5 \\
17.5\end{array}$ & $\begin{array}{l}14.0 \\
13.9\end{array}$ & $\begin{array}{l}100 \\
100\end{array}$ & $\begin{array}{c}6.809 \\
(0.339)\end{array}$ \\
\hline $\begin{array}{c}\text { SES } \\
\text { Low SES } \\
\text { Stable SES } \\
\text { Comfortable SES }\end{array}$ & $\begin{array}{c}5.0(47) \\
30.0(271) \\
65.0(596)\end{array}$ & $\begin{array}{l}14.9 \\
14.8 \\
15.8\end{array}$ & $\begin{array}{l}14.9 \\
14.0 \\
13.7\end{array}$ & $\begin{array}{l}10.7 \\
15.5 \\
13.8\end{array}$ & $\begin{array}{l}10.7 \\
12.9 \\
14.2\end{array}$ & $\begin{array}{l}12.7 \\
14.4 \\
14.9\end{array}$ & $\begin{array}{l}10.6 \\
15.5 \\
13.8\end{array}$ & $\begin{array}{l}25.5 \\
12.9 \\
13.8\end{array}$ & $\begin{array}{l}100 \\
100 \\
100\end{array}$ & $\begin{array}{l}7.235 \\
(0.842)\end{array}$ \\
\hline $\begin{array}{c}\text { Mother } \\
\text { Education } \\
\text { Level 1 } \\
\text { Level2 } \\
\text { Level } 3\end{array}$ & $\begin{array}{l}25.0(230) \\
24.0(224) \\
51.0(469)\end{array}$ & $\begin{array}{l}14.8 \\
12.0 \\
16.4 \\
\end{array}$ & $\begin{array}{l}13.5 \\
10.7 \\
16.2 \\
\end{array}$ & $\begin{array}{l}14.8 \\
14.3 \\
13.0 \\
\end{array}$ & $\begin{array}{l}14.7 \\
17.9 \\
11.5 \\
\end{array}$ & $\begin{array}{l}15.2 \\
14.8 \\
15.6\end{array}$ & $\begin{array}{l}14.4 \\
15.6 \\
12.8 \\
\end{array}$ & $\begin{array}{l}12.6 \\
14.7 \\
14.5\end{array}$ & $\begin{array}{l}100 \\
100 \\
100\end{array}$ & $\begin{array}{l}11.344 \\
(0.500)\end{array}$ \\
\hline $\begin{array}{c}\text { Father Education } \\
\text { Level } 1 \\
\text { Level } 2 \\
\text { Level } 3\end{array}$ & $\begin{array}{l}18.1(165) \\
23.1(210) \\
58.8(535)\end{array}$ & $\begin{array}{l}16.4 \\
20.0 \\
13.1\end{array}$ & $\begin{array}{l}10.9 \\
11.4 \\
15.7\end{array}$ & $\begin{array}{l}17.0 \\
12.9 \\
13.5\end{array}$ & $\begin{array}{l}14.5 \\
10.0 \\
13.8\end{array}$ & $\begin{array}{l}12.0 \\
12.9 \\
16.8\end{array}$ & $\begin{array}{l}14.6 \\
20.5 \\
12.1\end{array}$ & $\begin{array}{l}14.6 \\
12.3 \\
15.0\end{array}$ & $\begin{array}{l}100 \\
100 \\
100\end{array}$ & $\begin{array}{l}22.142 \\
(0.036)\end{array}$ \\
\hline Mean Age (SE) & & $\begin{array}{c}21.9 \\
(0.31)\end{array}$ & $\begin{array}{c}21.8 \\
(0.30)\end{array}$ & $\begin{array}{c}21.4 \\
(0.27)\end{array}$ & $\begin{array}{c}21.6 \\
(0.31)\end{array}$ & $\begin{array}{c}21.6 \\
(0.29)\end{array}$ & $\begin{array}{c}22.2 \\
(0.31)\end{array}$ & $\begin{array}{c}21.7 \\
(0.27)\end{array}$ & & $\begin{array}{c}9.617 \\
(0.142)\end{array}$ \\
\hline $\begin{array}{c}\text { BMI } \\
\text { Underweight } \\
\text { Normal weight } \\
\text { Overweight } \\
\text { Obese }\end{array}$ & $\begin{array}{l}12.6(117) \\
51.3(477) \\
21.4(199) \\
14.7(137)\end{array}$ & $\begin{array}{l}18.0 \\
14.3 \\
18.1 \\
13.9\end{array}$ & $\begin{array}{l}18.8 \\
14.3 \\
15.1 \\
10.9\end{array}$ & $\begin{array}{l}12.0 \\
14.7 \\
10.0 \\
13.1\end{array}$ & $\begin{array}{l}14.5 \\
13.0 \\
15.1 \\
14.6\end{array}$ & $\begin{array}{l}13.7 \\
15.3 \\
16.6 \\
11.7\end{array}$ & $\begin{array}{l}11.0 \\
13.8 \\
10.0 \\
20.5\end{array}$ & $\begin{array}{l}12.0 \\
14.6 \\
15.1 \\
15.3\end{array}$ & $\begin{array}{l}100 \\
100 \\
100 \\
100\end{array}$ & $\begin{array}{l}16.981 \\
(0.524)\end{array}$ \\
\hline
\end{tabular}

Notes: Mother and Father Education Levels are defined as follows: Level 1 is less than high school diploma, Level 2 is high school diploma, and Level 3 is post-secondary education. 


\subsubsection{Stimulus Materials}

Each participant was randomly assigned to one of the following groups (see Figures S1-S7): (1) thin models (2) average-sized models (3) heavy-sized models (4) thin celebrities (5) average-sized celebrities (6) heavy-sized celebrities and (7) neutral or control images. Although we tested fifteen different images in prior qualitative interviews, images of the following nine celebrities were used in the experiment: thin (Taylor Swift, Kendal Jenner, Angelina Jolie); average (Jennifer Lopez, Kim Kardashian, Kylie Jenner); heavy (Adele, Kelly Clarkson, and Ariel Winter). Each set of celebrity images contained two images of three different celebrities (see Figures S1-S3). This was done to aid in recognition of celebrities, though care was taken to ensure that the two images selected for each celebrity did not vary widely in body size and corresponded well with the body size category that these images were supposed to represent (For example, two average-sized images of Kim Kardashian were chosen while thinner than usual images of the celebrity were avoided). Each set of model images contained images of six different models (see Figures S4-S6). All images were edited to be on plain white backgrounds and were tested for cultural sensitivity during the qualitative interviews and only those deemed culturally appropriate for conservative Qatari society were used in the experiment. The neutral images consisted of light bulbs, buildings, and trees (Figure S7). All images were obtained either from publicly available sources or from Shutterstock as licensed to the authors' institution.

\subsection{Measures}

\subsubsection{Body Image Dissatisfaction (BID)}

To assess BID related to body size (our first dependent variable), participants were presented with Stunkard's nine figure rating silhouettes (Stunkard 1983) and were asked to evaluate their current body size and their ideal body size (see Figures A1 and A2 in Appendix A). Taking the difference between the ideal and current size produced a measure of body size dissatisfaction ranging from zero (no change) to $+/$ - eight (highest possible amount of change). As we were mainly interested in the desired direction of change in body size and not the amount of change, the difference score was collapsed into three nominal categories reflecting the direction of desired body size change: no change (zero difference score, ideal body size = current body size), thinner look (negative difference score, ideal body size less than current body size), and heavier look (positive difference score, ideal body size greater than current body size). Desiring a heavier body size is hereafter referred to as desire for heaviness. This was considered as a potential outcome of the experimental design because of previous literature supporting desire for heaviness in traditional Arab culture.

To assess BID related to body shape (our second dependent variable), participants were presented with five different body shape silhouettes: 1 "circle", 2 "triangle", 3 "inverted triangle", 4 "rectangle", and 5 "hourglass" and were asked to select their current and ideal body shape silhouettes (See Figures A3 and A4 in Appendix A). These questions allowed participants to convey their dissatisfaction with their body shape (irrespective of body size). The circle (or "plump") silhouette was excluded from further analyses as only 39 students selected it as their ideal shape. The remaining body shapes ( 2 through 5 ) were collapsed according to their distinct features. The curvaceous body shapes (2 and 5) featuring a smaller waist-to-hip ratio or larger hips, hereafter called "hips", were combined. Silhouette 3 distinctly featured a larger bust-to-waist ratio and is referred to as "bust" hereafter. Silhouette 4 or "rectangle" featured a non-curvaceous tubular body shape and is referred to as "ruler" hereafter.

\subsubsection{Evaluating Celebrities' Popularity and Bodies}

Following the experimental images and assessment of BID in size and shape, all respondents were asked whether they recognized, and how much they liked, twelve Western celebrities; nine out of these twelve celebrities were used in the experiment (see Section 4 in Appendix A). We found no existing measures in the literature that have been validated for this population and because of the lack of specificity of existing measures with respect to target celebrities, we adapted a measure from 
previous research conducted in Western setting (Harrison 1997), so that it uniquely assesses recognition and degree of liking of celebrities used in this study. Thumbnail-size headshots were provided next to names to help non-English speaking participants make connections between Western celebrity names and their faces (see Figure A5 in Appendix A). Participants were also asked to select their favorite celebrity from the list and to rate how much they liked the body shape of their favorite celebrity. Finally, respondents described the body shape of their favorite celebrity using the same five body shape silhouettes used in the self-rating question. From these questions three measures of celebrity influence were created: level of celebrity recognition, favorite celebrity body size, and favorite celebrity body shape.

A celebrity recognition score was created based on this measure and the score range was between 0 to 12 where 0 indicated that the respondent recognized none of the listed celebrities and 12 indicated they recognized all the listed celebrities. This variable was highly negatively skewed (Mean $=10.8$, Median $=12$; Skewness $=-2.5)$; it was further categorized to three levels of recognition low (scores $=0$ to 9 ), moderate (scores $=10$ or 11 ), and high (score $=12$ ) degree of recognition.

Participants' favorite celebrity body size was classified into "thin", "average", or "heavy" categories based on the researchers' classification and students' verification of these categories.

Participants described the body shape of their favorite celebrities using the same five body shape silhouettes described above, and were collapsed into the same three body-feature based categories used for their ideal body shapes: hips, bust, and ruler.

\subsubsection{Body Mass Index and Demographics}

Self-reported measures of weight and height allowed for estimates of body mass index (BMI, $\left.\mathrm{Kg} / \mathrm{m}^{2}\right)$. Respondents were classified into four BMI groups: underweight $(<18.5)$, normal weight (18.5 to 24.9), overweight (25.0 to 29.9), obese (30.0 or more). Participants were also asked to report their age, marital status, mother's and father's level of education, and family's economic status (see Section 3 in Appendix A).

\subsection{Sample Design}

A probability - based sampling approach was used to select a representative sample of female students $(n=2622)$ enrolled at Qatar University in September of 2016 from 10 strata: nationality (Qatari, Non-Qatari) and program year (5 levels). A total of 1345 students completed the online questionnaire (reached the last question in the survey) for a response rate of $51.7 \%$.

\subsection{Participants}

After initial data cleaning and data management, a total of 1145 observations were retained and used in the present analysis. The majority of students were Arabs (90.0\%), predominately Qataris $(63.0 \%)$, with ages ranging from 17 to 40 years and a mean age of 21.8 years $(\mathrm{SD}=3.6)$ (see Table 2).

Table 2. Univariates for Experiment Variables.

\begin{tabular}{lcc}
\hline \multicolumn{1}{c}{ Variables $(N)$} & Frequencies $n$ & Percentages $\%$ \\
\hline Desired Direction of Change in Body Weight $(N=1021)$ & \\
No Change & 183 & 17.9 \\
Weight Loss & 658 & 64.5 \\
Weight Gain & 180 & 17.6 \\
\hline Current Body Shape (original) $(N=1021)$ & & \\
Shape 1 & 135 & 13.2 \\
Shape 2 & 217 & 21.3 \\
Shape 3 & 133 & 13.0 \\
Shape 4 & 329 & 32.2 \\
Shape 5 & 207 & 20.3 \\
\hline
\end{tabular}


Table 2. Cont.

\begin{tabular}{lcc}
\hline \multicolumn{1}{c}{ Variables $(N)$} & Frequencies $\boldsymbol{n}$ & Percentages $\%$ \\
\hline Current Body shape (collapsed) $(N=886)$ & & \\
Hips & 424 & 47.9 \\
Bust & 133 & 15.0 \\
Ruler & 329 & 37.1 \\
\hline Ideal Body Shape (original) $(N=1018)$ & 39 & 3.9 \\
Shape 1 & 130 & 12.8 \\
Shape 2 & 178 & 17.5 \\
Shape 3 & 202 & 19.8 \\
Shape 4 & 469 & 46.0 \\
Shape 5 & & \\
\hline Ideal Body Shape (collapsed) $(N=979)$ & 599 & 61.2 \\
Hips & 178 & 18.2 \\
Bust & 202 & 20.6 \\
Ruler & & \\
\hline Favorite Celebrity's Body Weight $(N=967)$ & 438 & 45.3 \\
Thin Celebrity & 439 & 9.3 \\
Normal Celebrity & 90 & 47.4 \\
Heavy Celebrity & & 22.1 \\
\hline Favorite Celebrity's Body Shape $(N=967)$ & 424 & 30.5 \\
Hips & 198 & 16.5 \\
Bust & 272 & 65.9 \\
Ruler & 168 & \\
\hline Celebrity Recognition Levels $(N=1016)$ & 670 & ( $N$ ) \\
Minimum & & \\
Moderate & & \\
High & & \\
\hline
\end{tabular}

Notes: Celebrity Recognition Levels variable was created based on celebrity recognition score of 0 to 12 where 0 indicates recognition of none of the listed celebrities and 12 indicates recognition of all the listed celebrities. This variable was further categorized to three levels of recognition with score of 0 to $9=$ Low, 10 to $11=$ Moderate, $12=$ High degree of recognition .

\subsection{Analytical Procedures}

The univariate distribution of body size and body shape variables related to participants and their favorite celebrities was examined. The Chi-square test of proportions was used to compare the distribution of socio-demographic variables and BMI categories across treatment and control groups.

We adopted a nominal approach rather than an ordinal approach to modeling because our original hypotheses were about the desire for change in body size (towards thinness versus heaviness) relative to no change as opposed to the amount of change in either direction of the BID scale. To this end, two sets of multinomial logistic regression models were fit to the data. The first set of models simultaneously estimated the odds of desiring a change in current body size towards a thinner or a heavier look relative to no change for each of the treatment groups versus the control group. The second set of models estimated the odds of desiring the larger hips and bust versus the ruler as the ideal body shape silhouette. In each set of models, corresponding odds ratios (OR) and standard errors (SE) in exponential form were estimated for each nominal level of the dependent variable with and without other measured control variables. In the latter approach, variables were added to the simplest model (treatment main effects only) in a forward stepwise fashion. This allowed for the evaluation of the contribution of each predictor to the model using a variety of fit statistics, including the F-adjusted Wald test and the F-adjusted mean residual goodness of fit test. Data diagnostics assessed outliers, influential observations, and violations of model assumptions including the Suest-based Huasmen test for independence of irrelevant alternative (IIA) assumption (Hausman and McFadden 1984). Potential 
interactions between the treatments and favorite celebrity's body sizes and shapes were tested by fitting multinomial regression models with only the main favorite celebrity effects, main treatment effects, and relevant two-way interaction effects. The corresponding marginal effects in these models with interactions were also estimated and plotted.

A series of sensitivity analyses were conducted to confirm the robustness of the results. First, we re-ran our multinomial models with study-specific weights used for all of our descriptive analyses. These weights were computed to adjust for non-response as well as unequal probability of selection resulting from the sample design. Second, we re-ran our multinomial models with BMI as a continuous instead of categorical variable. We also conducted alternative analyses that treated BID in size (our first dependent variable) as an ordinal ( \pm eight) instead of multinomial variable. First, we ran analysis of variance (ANOVA) with our experimental groups as independent variable. We also ran analysis of covariance (ANCOVA) with our experimental groups as main independent variable and continuous BMI as the covariate. Additionally, after confirming that the proportional odds assumption was met, we also fitted the same models as in the multinomial approach, but using ordinal logistic regression models instead. Two-tailed $p$-values $<0.05$ were considered statistically significant. All statistical analyses were performed with Stata version 13.1 (StataCorp 2013).

\section{Results}

\subsection{Experimental Effects on BID in Body Size}

Table 3 presents results from three multinomial logistic regression models for BID in size as the dependent variable. Model 1 in Table 3 shows treatment effects for the desire for thinness and for heaviness with respondents who did not desire change in their current body size were considered the reference category. Results from this model did not provide any evidence in support of the desire for thinness among those who viewed thin celebrities $(\mathrm{OR}=0.928, \mathrm{SE}=0.274)$ or those who viewed thin models $(\mathrm{OR}=1.524$ and $\mathrm{SE}=0.476)$. In fact, viewing images of thin celebrities or thin models was associated with the desire for heaviness (thin celebrities: $\mathrm{OR}=1.427, \mathrm{SE}=0.548$; thin models: $\mathrm{OR}=2.080, \mathrm{SE}=0.826)$, though these estimates were not statistically significant $(p<0.1)$.

Table 3. Multinomial Logistic Models of Body Size Change with and without Interactive Effects.

\begin{tabular}{|c|c|c|c|c|c|c|c|}
\hline \multirow{2}{*}{ Variables } & \multirow{2}{*}{$\begin{array}{c}\text { Moderating } \\
\text { Variables }\end{array}$} & \multicolumn{2}{|c|}{ Model 1} & \multicolumn{2}{|c|}{ Model 2} & \multicolumn{2}{|c|}{ Model 3} \\
\hline & & $\begin{array}{l}\text { Thinner } \\
\text { OR (SE) }\end{array}$ & $\begin{array}{l}\text { Heavier } \\
\text { OR (SE) }\end{array}$ & $\begin{array}{l}\text { Thinner } \\
\text { OR (SE) }\end{array}$ & $\begin{array}{l}\text { Heavier } \\
\text { OR (SE) }\end{array}$ & $\begin{array}{l}\text { Thinner } \\
\text { OR (SE) }\end{array}$ & $\begin{array}{l}\text { Heavier } \\
\text { OR (SE) }\end{array}$ \\
\hline $\begin{array}{l}\text { Treatment group: } \\
\text { (baseline: neutral) } \\
\text { Thin Models }\end{array}$ & & $\begin{array}{c}1.524 \\
(0.476)\end{array}$ & $\begin{array}{c}2.080 \\
(0.826)\end{array}$ & $\begin{array}{c}1.572 \\
(0.517)\end{array}$ & $\begin{array}{c}2.055 \\
(0.858)\end{array}$ & $\begin{array}{c}1.520 \\
(1.958)\end{array}$ & $\begin{array}{c}1.304 \\
(1.878)\end{array}$ \\
\hline $\begin{array}{l}\text { Treatment group: } \\
\text { Thin Celebrities }\end{array}$ & & $\begin{array}{c}0.928 \\
(0.274)\end{array}$ & $\begin{array}{c}1.427 \\
(0.548)\end{array}$ & $\begin{array}{c}0.815 \\
(0.250)\end{array}$ & $\begin{array}{l}1.370 \\
(0.544)\end{array}$ & $\begin{array}{c}0.177 \\
(0.170)\end{array}$ & $\begin{array}{c}0.087 \\
(0.121)\end{array}$ \\
\hline $\begin{array}{l}\text { Treatment group: } \\
\text { Normal Models }\end{array}$ & & $\begin{array}{c}0.905 \\
(0.270)\end{array}$ & $\begin{array}{c}1.323 \\
(0.517)\end{array}$ & $\begin{array}{c}0.902 \\
(0.285)\end{array}$ & $\begin{array}{l}1.349 \\
(0.554)\end{array}$ & $\begin{array}{c}0.507 \\
(0.555)\end{array}$ & $\begin{array}{c}0.870 \\
(1.061)\end{array}$ \\
\hline $\begin{array}{l}\text { Treatment group: } \\
\text { Normal Celebrities }\end{array}$ & & $\begin{array}{c}1.022 \\
(0.311) \\
\end{array}$ & $\begin{array}{c}1.533 \\
(0.604)\end{array}$ & $\begin{array}{c}0.959 \\
(0.305) \\
\end{array}$ & $\begin{array}{c}1.546 \\
(0.632)\end{array}$ & $\begin{array}{c}0.101 * * \\
(0.103)\end{array}$ & $\begin{array}{c}0.261 \\
(0.294)\end{array}$ \\
\hline $\begin{array}{l}\text { Treatment group: } \\
\text { Heavy Models }\end{array}$ & & $\begin{array}{l}1.438 \\
(0.450)\end{array}$ & $\begin{array}{c}1.812 \\
(0.730)\end{array}$ & $\begin{array}{c}1.510 \\
(0.505)\end{array}$ & $\begin{array}{l}1.771 \\
(0.761)\end{array}$ & $\begin{array}{c}0.443 \\
(0.489)\end{array}$ & $\begin{array}{c}0.217 \\
(0.325)\end{array}$ \\
\hline $\begin{array}{l}\text { Treatment group: } \\
\text { Heavy Celebrities }\end{array}$ & & $\begin{array}{c}1.362 \\
(0.422)\end{array}$ & $\begin{array}{l}1.219 \\
(0.512)\end{array}$ & $\begin{array}{c}1.335 \\
(0.437)\end{array}$ & $\begin{array}{l}1.214 \\
(0.533)\end{array}$ & $\begin{array}{c}1.333 \\
(0.442)\end{array}$ & $\begin{array}{l}1.207 \\
(0.539)\end{array}$ \\
\hline $\begin{array}{l}\text { Favorite Celebrity: } \\
\text { (baseline heavy) } \\
\text { Thin }\end{array}$ & & & & $\begin{array}{c}0.976 \\
(0.298)\end{array}$ & $\begin{array}{c}0.940 \\
(0.356)\end{array}$ & $\begin{array}{c}0.273 \\
(0.212)\end{array}$ & $\begin{array}{l}0.162 * \\
(0.146)\end{array}$ \\
\hline $\begin{array}{l}\text { Favorite Celebrity: } \\
\text { (baseline heavy) } \\
\text { Normal }\end{array}$ & & & & $\begin{array}{c}1.314 \\
(0.407)\end{array}$ & $\begin{array}{c}1.114 \\
(0.427)\end{array}$ & $\begin{array}{c}0.669 \\
(0.535)\end{array}$ & $\begin{array}{c}0.540 \\
(0.490)\end{array}$ \\
\hline
\end{tabular}


Table 3. Cont.

\begin{tabular}{|c|c|c|c|c|c|c|c|}
\hline \multirow[b]{2}{*}{ Variables } & \multirow{2}{*}{$\begin{array}{l}\text { Moderating } \\
\text { Variables }\end{array}$} & \multicolumn{2}{|c|}{ Model 1} & \multicolumn{2}{|c|}{ Model 2} & \multicolumn{2}{|c|}{ Model 3} \\
\hline & & $\begin{array}{l}\text { Thinner } \\
\text { OR (SE) }\end{array}$ & $\begin{array}{l}\text { Heavier } \\
\text { OR (SE) }\end{array}$ & $\begin{array}{l}\text { Thinner } \\
\text { OR (SE) }\end{array}$ & $\begin{array}{l}\text { Heavier } \\
\text { OR (SE) }\end{array}$ & $\begin{array}{l}\text { Thinner } \\
\text { OR (SE) }\end{array}$ & $\begin{array}{l}\text { Heavier } \\
\text { OR (SE) }\end{array}$ \\
\hline $\begin{array}{l}\text { Treatment group } \\
\text { (baseline: neutral) } \\
\text { Thin Models }\end{array}$ & $\begin{array}{c}\text { Favorite Celebrity: } \\
\text { (baseline heavy) } \\
\text { Thin }\end{array}$ & & & & & $\begin{array}{c}1.342 \\
(1.804)\end{array}$ & $\begin{array}{c}3.085 \\
(4.688)\end{array}$ \\
\hline $\begin{array}{l}\text { Treatment group } \\
\text { Thin Celebrities }\end{array}$ & $\begin{array}{c}\text { Favorite Celebrity: } \\
\text { Thin }\end{array}$ & & & & & $\begin{array}{l}7.442 * \\
(7.616)\end{array}$ & $\begin{array}{l}35.597 * \\
(52.224)\end{array}$ \\
\hline $\begin{array}{l}\text { Treatment group } \\
\text { Normal Models }\end{array}$ & $\begin{array}{c}\text { Favorite Celebrity: } \\
\text { Thin }\end{array}$ & & & & & $\begin{array}{c}2.928 \\
(3.411)\end{array}$ & $\begin{array}{c}2.777 \\
(3.694)\end{array}$ \\
\hline $\begin{array}{l}\text { Treatment group } \\
\text { Normal Celebrities }\end{array}$ & $\begin{array}{c}\text { Favorite Celebrity: } \\
\text { Thin }\end{array}$ & & & & & $\begin{array}{l}20.132 * * \\
(21.807)\end{array}$ & $\begin{array}{l}14.397 * \\
(17.712)\end{array}$ \\
\hline $\begin{array}{l}\text { Treatment group } \\
\text { Heavy Models }\end{array}$ & $\begin{array}{c}\text { Favorite Celebrity: } \\
\text { Thin }\end{array}$ & & & & & $\begin{array}{c}4.067 \\
(4.783)\end{array}$ & $\begin{array}{c}17.825 \\
(28.165)\end{array}$ \\
\hline $\begin{array}{l}\text { Treatment group } \\
\text { (baseline: neutral) } \\
\text { Thin Models }\end{array}$ & $\begin{array}{l}\text { Favorite Celebrity: } \\
\text { (baseline heavy) } \\
\text { Normal }\end{array}$ & & & & & $\begin{array}{c}0.665 \\
(0.905)\end{array}$ & $\begin{array}{r}0.755 \\
(1.159)\end{array}$ \\
\hline $\begin{array}{l}\text { Treatment group } \\
\text { Thin Celebrities }\end{array}$ & $\begin{array}{c}\text { Favorite Celebrity: } \\
\text { Normal }\end{array}$ & & & & & $\begin{array}{l}3.293 \\
(3.443)\end{array}$ & $\begin{array}{c}10.035 \\
(14.833)\end{array}$ \\
\hline $\begin{array}{l}\text { Treatment group } \\
\text { Normal Models }\end{array}$ & $\begin{array}{c}\text { Favorite Celebrity: } \\
\text { Normal }\end{array}$ & & & & & $\begin{array}{c}1.041 \\
(1.215)\end{array}$ & $\begin{array}{c}0.794 \\
(1.044) \\
\end{array}$ \\
\hline $\begin{array}{l}\text { Treatment group } \\
\text { Normal Celebrities }\end{array}$ & $\begin{array}{c}\text { Favorite Celebrity: } \\
\text { Normal }\end{array}$ & & & & & $\begin{array}{c}5.607 \\
(6.201)\end{array}$ & $\begin{array}{c}3.088 \\
(3.854)\end{array}$ \\
\hline $\begin{array}{l}\text { Treatment group } \\
\text { Heavy Models }\end{array}$ & $\begin{array}{c}\text { Favorite Celebrity: } \\
\text { Normal }\end{array}$ & & & & & $\begin{array}{c}2.937 \\
(3.507)\end{array}$ & $\begin{array}{c}4.631 \\
(7.395)\end{array}$ \\
\hline \multirow[t]{2}{*}{ Constant } & & $3.161 * *$ & 0.677 & $2.980 * *$ & 0.695 & $7.897 * *$ & 2.300 \\
\hline & & $(0.651)$ & $(0.191)$ & $(1.023)$ & $(0.308)$ & $(5.996)$ & $(1.978)$ \\
\hline Observations & & 1021 & 1021 & 960 & 960 & 960 & 960 \\
\hline Pseudo R-squared & & 0.00573 & 0.00573 & 0.00927 & 0.00927 & 0.0226 & 0.0226 \\
\hline 11 & & -910.8 & -910.8 & -850.4 & -850.4 & -838.9 & -838.9 \\
\hline $\mathrm{df}$ & & 12 & 12 & 16 & 16 & 36 & 36 \\
\hline chi2 & & 10.51 & 10.51 & 15.91 & 15.91 & 38.83 & 38.83 \\
\hline
\end{tabular}

\subsection{Moderation of Experimental Effects on BID in Body Size by Favorite Celebrity Body Size}

Model 2 in Table 3 presents results with treatment effects in addition to main effects of favorite celebrity's body size. Compared to favoring a heavy-sized celebrity, neither favoring a thin celebrity $(\mathrm{OR}=0.976)$ or favoring an average-sized celebrity $(\mathrm{OR}=1.314)$ were significantly associated with a desire for thinness relative to those who did not desire change in their current body size $(p<0.1)$. However, when interaction terms were added to Model 3, strong interactive effects were found for the thin-sized and average-sized celebrity treatment groups when respondents favored thin-sized celebrities. The average celebrity treatment had a larger effect than the thin celebrity on the desire for thinness (thin celebrity: $\mathrm{OR}=7.442, \mathrm{SE}=7.616, p<0.05$; average-sized celebrity: $\mathrm{OR}=20.132$, $\mathrm{SE}=21.807, p<0.05)$. However, the opposite was true for the desire for heaviness, with stronger effects being found for thin celebrities (thin celebrity: $\mathrm{OR}=35.597, \mathrm{SE}=52.224, p<0.05$ and average-sized celebrity: $\mathrm{OR}=14.397, \mathrm{SE}=17.712, p<0.05)$ compared to heavy celebrity. Marginal effects from this model were estimated and plotted. 
Figure 1 plots the predicted probability (Pr) of desiring a thinner or heavier body contingent on the body size of the respondent's favorite celebrity, given that the respondent viewed thin celebrities. Respondents who favored a heavy celebrity, but viewed images of thin celebrities were significantly more likely to desire a thinner look $(\operatorname{Pr}=0.565, \mathrm{SE}=0.081, p<0.001)$ than a heavier look $(\operatorname{Pr}=0.137$, $\mathrm{SE}=0.047, p<0.001)$. However, this difference narrowed when respondents favored thin celebrities and viewed thin celebrities $(\operatorname{Pr}=0.521 \mathrm{SE}=0.128, p<0.001$ for heavy versus $\operatorname{Pr}=0.336 \mathrm{SE}=0.139$, $p<0.05$ for thin). Thus, in the thin celebrity exposure case, favoring a thin celebrity increased the desire for heaviness.

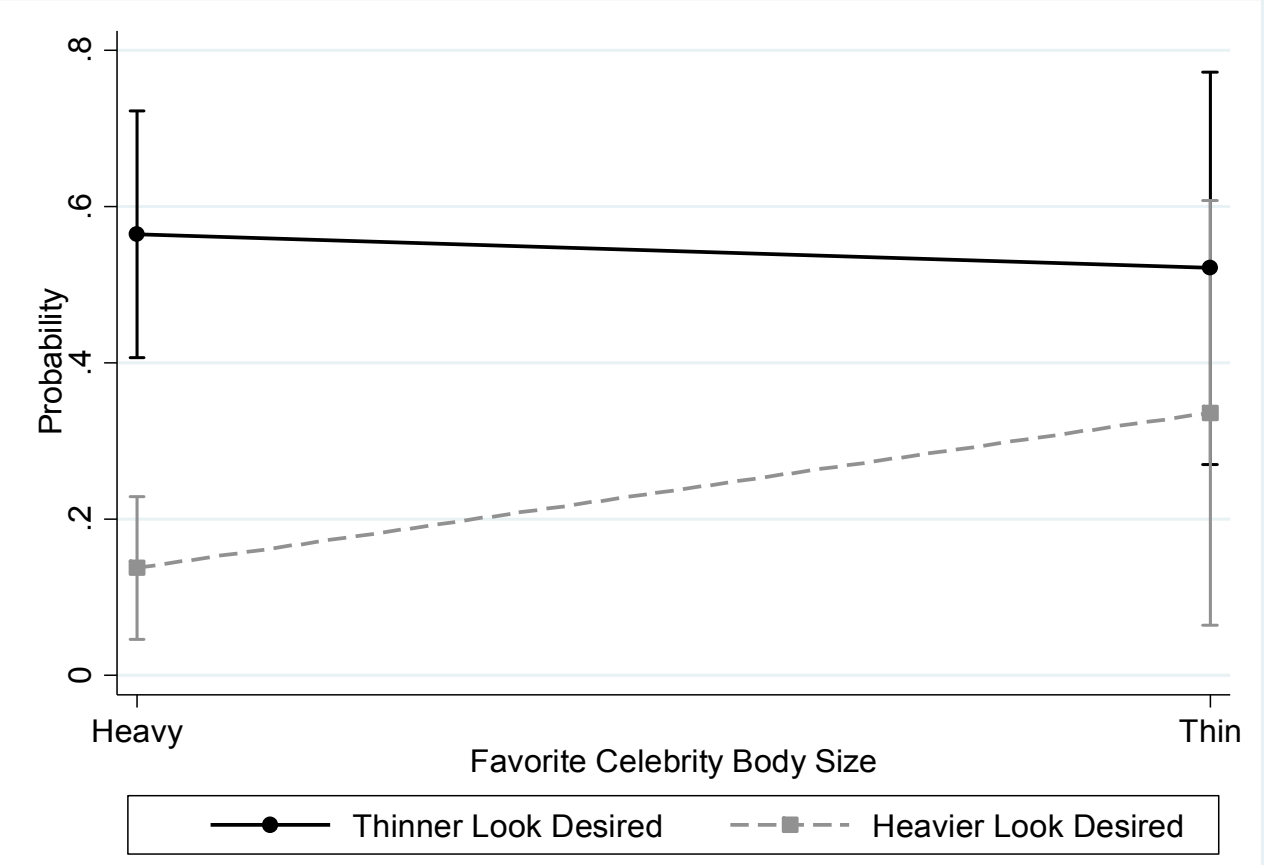

Figure 1. Predictive Margins for Thin Celebrities Treatment and Favorite Celebrity Body Size (Thin versus Heavy).

Figure 2 examines the predicted probabilities when respondents viewed average-sized celebrities. Again, respondents who viewed the average-sized celebrities had a higher probability of wanting to lose rather than gain weight. This plot demonstrates that respondents who favored a thin-sized celebrity (and viewed average-sized celebrities) were significantly more likely to desire a thinner look $(\operatorname{Pr}=0.733, \mathrm{SE}=0.066, p<0.001)$ than those who favored a heavy-sized celebrity $(\operatorname{Pr}=0.454, \mathrm{SE}=0.081$, $p<0.001)$. In contrast to the thin celebrity exposure case shown in Figure 1, favoring a thin celebrity intensified the desire for thinness only when exposed to images of average-sized celebrities.

\subsection{Experimental Effects on BID in Body Shape}

Multinomial regression models for desiring hips and bust as ideal body shapes were fit to the data, with the ruler body shape as the baseline (see Table 4). In a model containing only treatment effects, respondents who viewed thin models were significantly more likely to desire a body shape with hips ( $\mathrm{OR}=2.437$ and $\mathrm{SE}=0.742, p<0.010)$. When added to the model, respondent $\mathrm{BMI}$ is positive predictor of desiring a silhouette with hips $(\mathrm{OR}=1.087$ and $\mathrm{SE}=0.024, p<0.001)$. Unsurprisingly, liking a celebrity with hips was positively associated with desiring an ideal body shape with hips $(\mathrm{OR}=2.818$ and $\mathrm{SE}=0.735)$ and the same was true for bust as an ideal body shape (OR $=3.505$ and $\mathrm{SE}=1.187)$. 

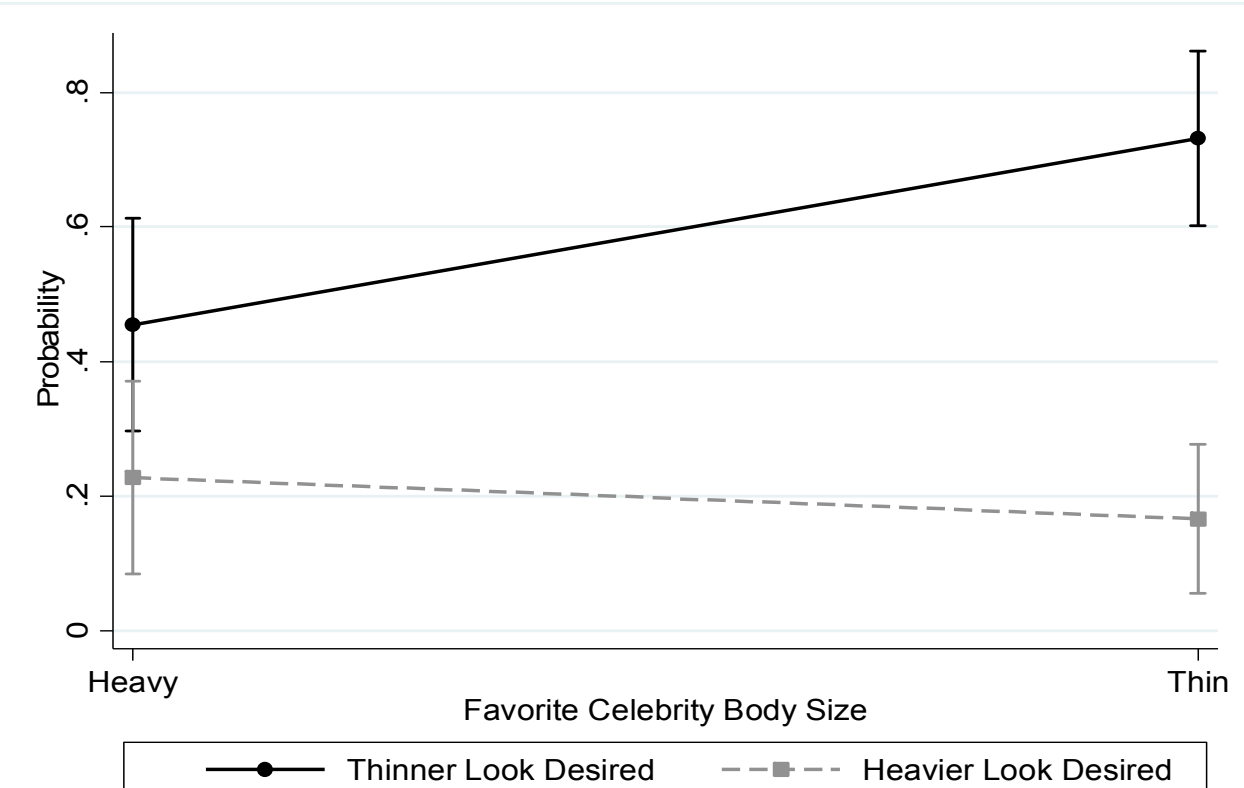

Figure 2. Predictive Margins for Average-sized celebrities Treatment and Favorite Celebrity Body Size (Thin versus Heavy).

Table 4. Multinomial Logistic Models for Ideal (Desired) Body Shape.

\begin{tabular}{|c|c|c|c|c|c|c|c|c|c|c|}
\hline \multirow{2}{*}{ Variables } & \multicolumn{2}{|c|}{ Model 1} & \multicolumn{2}{|c|}{ Model 2} & \multicolumn{2}{|c|}{ Model 3} & \multicolumn{2}{|c|}{ Model 4} & \multicolumn{2}{|c|}{ Model 5} \\
\hline & $\begin{array}{l}\text { Hips } \\
\text { OR (SE) }\end{array}$ & $\begin{array}{c}\text { Bust } \\
\text { OR (SE) }\end{array}$ & $\begin{array}{l}\text { Hips } \\
\text { OR (SE) }\end{array}$ & $\begin{array}{c}\text { Bust } \\
\text { OR (SE) }\end{array}$ & $\begin{array}{l}\text { Hips } \\
\text { OR (SE) }\end{array}$ & $\begin{array}{c}\text { Bust } \\
\text { OR (SE) }\end{array}$ & $\begin{array}{l}\text { Hips } \\
\text { OR (SE) }\end{array}$ & $\begin{array}{c}\text { Bust } \\
\text { OR (SE) }\end{array}$ & $\begin{array}{l}\text { Hips } \\
\text { OR (SE) }\end{array}$ & $\begin{array}{c}\text { Bust } \\
\text { OR (SE) }\end{array}$ \\
\hline $\begin{array}{l}\text { Treatment group: } \\
\text { (baseline: neutral) } \\
\text { Thin Models }\end{array}$ & $\begin{array}{l}2.437 * * \\
(0.742)\end{array}$ & $\begin{array}{c}1.636 \\
(0.636)\end{array}$ & $\begin{array}{l}2.922 * * \\
(0.983)\end{array}$ & $\begin{array}{l}2.078 * \\
(0.878)\end{array}$ & $\begin{array}{l}4.196^{* *} \\
(1.677)\end{array}$ & $\begin{array}{l}3.240 * \\
(1.562)\end{array}$ & $\begin{array}{l}3.594 * * \\
(1.526)\end{array}$ & $\begin{array}{c}2.400 \\
(1.273)\end{array}$ & $\begin{array}{l}3.612 * * \\
(1.563)\end{array}$ & $\begin{array}{c}2.389 \\
(1.278)\end{array}$ \\
\hline $\begin{array}{l}\text { Treatment group: } \\
\text { Thin Celebrities }\end{array}$ & $\begin{array}{c}1.553 \\
(0.457)\end{array}$ & $\begin{array}{c}1.722 \\
(0.629)\end{array}$ & $\begin{array}{c}1.801 \\
(0.577)\end{array}$ & $\begin{array}{l}2.123 \\
(0.834)\end{array}$ & $\begin{array}{l}1.971 \\
(0.721)\end{array}$ & $\begin{array}{l}2.421^{*} \\
(1.066)\end{array}$ & $\begin{array}{l}2.212 * \\
(0.901)\end{array}$ & $\begin{array}{l}3.200 * \\
(1.574)\end{array}$ & $\begin{array}{c}2.234 \\
(0.926)\end{array}$ & $\begin{array}{l}3.193 * \\
(1.577)\end{array}$ \\
\hline $\begin{array}{l}\text { Treatment group: } \\
\text { Normal Models }\end{array}$ & $\begin{array}{c}1.463 \\
(0.437)\end{array}$ & $\begin{array}{c}1.385 \\
(0.526)\end{array}$ & $\begin{array}{c}1.552 \\
(0.502)\end{array}$ & $\begin{array}{l}1.535 \\
(0.628)\end{array}$ & $\begin{array}{l}1.987 * \\
(0.736)\end{array}$ & $\begin{array}{l}2.070 \\
(0.937)\end{array}$ & $\begin{array}{l}1.502 \\
(0.615)\end{array}$ & $\begin{array}{c}1.990 \\
(1.023)\end{array}$ & $\begin{array}{l}1.474 \\
(0.620)\end{array}$ & $\begin{array}{l}1.975 \\
(1.023)\end{array}$ \\
\hline $\begin{array}{l}\text { Treatment group: } \\
\text { Normal Celebrities }\end{array}$ & $\begin{array}{c}1.117 \\
(0.325)\end{array}$ & $\begin{array}{c}1.113 \\
(0.416)\end{array}$ & $\begin{array}{c}1.141 \\
(0.353)\end{array}$ & $\begin{array}{l}1.202 \\
(0.477)\end{array}$ & $\begin{array}{l}1.628 \\
(0.592)\end{array}$ & $\begin{array}{l}1.911 \\
(0.855)\end{array}$ & $\begin{array}{l}1.257 \\
(0.500)\end{array}$ & $\begin{array}{l}1.730 \\
(0.858)\end{array}$ & $\begin{array}{c}1.308 \\
(0.531)\end{array}$ & $\begin{array}{l}1.713 \\
(0.859)\end{array}$ \\
\hline $\begin{array}{l}\text { Treatment group: } \\
\text { Heavy Models }\end{array}$ & $\begin{array}{l}1.479 \\
(0.429)\end{array}$ & $\begin{array}{l}1.345 \\
(0.498)\end{array}$ & $\begin{array}{c}1.479 \\
(0.449)\end{array}$ & $\begin{array}{l}1.204 \\
(0.478)\end{array}$ & $\begin{array}{l}1.591 \\
(0.561)\end{array}$ & $\begin{array}{l}1.238 \\
(0.559)\end{array}$ & $\begin{array}{c}1.435 \\
(0.559)\end{array}$ & $\begin{array}{c}1.399 \\
(0.704)\end{array}$ & $\begin{array}{l}1.437 \\
(0.572)\end{array}$ & $\begin{array}{l}1.359 \\
(0.690)\end{array}$ \\
\hline $\begin{array}{l}\text { Treatment group: } \\
\text { Heavy Celebrities }\end{array}$ & $\begin{array}{l}1.497 \\
(0.438)\end{array}$ & $\begin{array}{l}1.286 \\
(0.484)\end{array}$ & $\begin{array}{l}1.564 \\
(0.503)\end{array}$ & $\begin{array}{l}1.571 \\
(0.638)\end{array}$ & $\begin{array}{l}3.287^{* *} \\
(1.339)\end{array}$ & $\begin{array}{l}2.726^{*} \\
(1.351)\end{array}$ & $\begin{array}{l}3.266^{*} \\
(1.502)\end{array}$ & $\begin{array}{l}3.895^{*} \\
(2.164)\end{array}$ & $\begin{array}{l}3.279^{*} \\
(1.539)\end{array}$ & $\begin{array}{l}3.962 * \\
(2.213)\end{array}$ \\
\hline Current BMI & & & $\begin{array}{l}1.087^{* *} \\
(0.020)\end{array}$ & $\begin{array}{l}1.022 \\
(0.024)\end{array}$ & $\begin{array}{l}1.061 * \\
(0.026)\end{array}$ & $\begin{array}{l}1.036 \\
(0.030)\end{array}$ & $\begin{array}{l}1.057 * \\
(0.027)\end{array}$ & $\begin{array}{c}1.040 \\
(0.032)\end{array}$ & $\begin{array}{l}1.093^{* *} \\
(0.037)\end{array}$ & $\begin{array}{c}1.055 \\
(0.042)\end{array}$ \\
\hline $\begin{array}{l}\text { Body Shape Now: } \\
\text { (baseline: Ruler) } \\
\text { Hips }\end{array}$ & & & & & $\begin{array}{l}8.116 * * \\
(2.042)\end{array}$ & $\begin{array}{l}2.423 * * \\
(0.770)\end{array}$ & $\begin{array}{l}7.232 * * \\
(1.961)\end{array}$ & $\begin{array}{l}2.517^{* *} \\
(0.868)\end{array}$ & $\begin{array}{l}8.463 * * \\
(2.357)\end{array}$ & $\begin{array}{l}2.784^{* * *} \\
(0.973)\end{array}$ \\
\hline $\begin{array}{c}\text { Body Shape Now: } \\
\text { Bust }\end{array}$ & & & & & $\begin{array}{l}3.898 * * \\
(1.366)\end{array}$ & $\begin{array}{l}8.415^{* *} \\
(3.103)\end{array}$ & $\begin{array}{l}2.938^{* *} \\
(1.065)\end{array}$ & $\begin{array}{l}8.146^{* *} \\
(3.189)\end{array}$ & $\begin{array}{c}3.137^{* *} \\
(1.153)\end{array}$ & $\begin{array}{l}8.525^{* *} \\
(3.362)\end{array}$ \\
\hline $\begin{array}{c}\text { Favorite Celeb } \\
\text { Body Shape: } \\
\text { (baseline: Ruler) } \\
\text { Hips } \\
\end{array}$ & & & & & & & $\begin{array}{l}2.818^{* *} \\
(0.735)\end{array}$ & $\begin{array}{l}1.183 \\
(0.405)\end{array}$ & $\begin{array}{l}2.556 * * \\
(0.682)\end{array}$ & $\begin{array}{l}1.110 \\
(0.385)\end{array}$ \\
\hline $\begin{array}{c}\text { Favorite Celeb } \\
\text { Body Shape: } \\
\text { Bust }\end{array}$ & & & & & & & $\begin{array}{c}0.916 \\
(0.279)\end{array}$ & $\begin{array}{l}3.505^{* *} \\
(1.187)\end{array}$ & $\begin{array}{c}0.799 \\
(0.247)\end{array}$ & $\begin{array}{l}3.142 * * \\
(1.074)\end{array}$ \\
\hline $\begin{array}{c}\text { Body Weight } \\
\text { Change Desired: } \\
\text { (baseline: No change) } \\
\text { Weight Loss }\end{array}$ & & & & & & & & & $\begin{array}{l}1.254 \\
(0.384)\end{array}$ & $\begin{array}{l}1.467 \\
(0.556)\end{array}$ \\
\hline $\begin{array}{c}\text { Body Weight Change } \\
\text { Desired: } \\
\text { Weight Gain }\end{array}$ & & & & & & & & & $\begin{array}{l}3.040 * * \\
(1.083)\end{array}$ & $\begin{array}{r}2.201 \\
(0.955) \\
\end{array}$ \\
\hline
\end{tabular}


Table 4. Cont.

\begin{tabular}{ccccccccccccc}
\hline \multirow{2}{*}{ Variables } & \multicolumn{2}{c}{ Model 1 } & \multicolumn{2}{c}{ Model 2 } & \multicolumn{2}{c}{ Model 3 } & \multicolumn{2}{c}{ Model 4 } & \multicolumn{2}{c}{ Model 5 } \\
& Hips & Bust & Hips & Bust & Hips & Bust & Hips & Bust & Hips & Bust \\
& OR (SE) & OR (SE) & OR (SE) & OR (SE) & OR (SE) & OR (SE) & OR (SE) & OR (SE) & OR (SE) & OR (SE) \\
\hline Constant & $2.051^{* *}$ & 0.667 & $0.291^{*}$ & 0.378 & $0.173 * *$ & $0.125^{* *}$ & $0.140^{* *}$ & $0.065^{* *}$ & $0.047^{* *}$ & $0.033^{* *}$ \\
\hline Observations & $(0.401)$ & $(0.169)$ & $(0.141)$ & $(0.229)$ & $(0.103)$ & $(0.089)$ & $(0.092)$ & $(0.052)$ & $(0.037)$ & $(0.032)$ \\
\hline Pseudo R-squared & 9.00683 & 0.00683 & 0.0274 & 0.0274 & 0.135 & 0.135 & 0.185 & 0.185 & 0.195 & 0.195 \\
\hline ll & -910.3 & -910.3 & -793.8 & -793.8 & -624.2 & -624.2 & -515.4 & -515.4 & -506.6 & -506.6 \\
\hline df_m & 12 & 12 & 14 & 14 & 18 & 18 & 22 & 22 & 26 \\
\hline chi2 & 12.52 & 12.52 & 44.79 & 44.79 & 194.2 & 194.2 & 234.2 & 234.2 & 245.7 & 245.7 \\
\hline
\end{tabular}

Notes: Odds Ratio (OR) estimates and exponentiated standard error (SE) in parentheses. Log-likelihood Ratio (11),

Degrees of Freedom (df), Chi Square Statistics (Chi2). Ideal Body Shape is dependent variable defined as: Hips,

Bust, and Ruler (reference group). ${ }^{* *} p<0.01,{ }^{*} p<0.05$.

\subsection{Moderation of Experimental Effects on BID in Body Shape by Favorite Celebrity Body Shape}

Table 5 reports average marginal effects models with interaction terms used to test for moderation by favorite celebrity's body shape. Significant marginal effects were identified for the interaction between favorite celebrity's body shape and the thin-sized model treatment on desiring silhouettes with hips $(\operatorname{Pr}=0.185, p<0.01)$ and bust $(\operatorname{Pr}=0.196, p<0.01)$.

Table 5. Average Marginal Effects on Ideal Body Shape and Celebrity's Shape Interactions.

\begin{tabular}{|c|c|c|c|c|c|c|c|}
\hline \multirow{2}{*}{ Variables } & \multirow{2}{*}{$\begin{array}{l}\text { Moderating } \\
\text { Variables }\end{array}$} & \multicolumn{3}{|c|}{ Ideal Body Shape: Hips } & \multicolumn{3}{|c|}{ Ideal Body Shape: Bust } \\
\hline & & M.E. & SE & $p$-Val. & M.E. & SE & $p$-Val. \\
\hline Thin Models & & 0.147 & 0.055 & 0.008 & -0.049 & 0.042 & 0.246 \\
\hline Thin Celebrities & & 0.030 & 0.058 & 0.601 & 0.045 & 0.048 & 0.347 \\
\hline Average Models & & 0.015 & 0.063 & 0.808 & 0.002 & 0.049 & 0.965 \\
\hline Average Celebrities & & -0.015 & 0.063 & 0.805 & -0.001 & 0.050 & 0.989 \\
\hline Heavy Models & & 0.021 & 0.060 & 0.724 & 0.008 & 0.049 & 0.876 \\
\hline Heavy Celebrities & & 0.050 & 0.060 & 0.398 & 0.008 & 0.048 & 0.862 \\
\hline Fav Celeb Shape: Hips & & 0.185 & 0.038 & 0.000 & -0.054 & 0.032 & 0.087 \\
\hline Fav Celeb Shape: Bust & & -0.206 & 0.049 & 0.000 & 0.196 & 0.045 & 0.000 \\
\hline \multirow{2}{*}{ Thin Models } & Celeb: Hips & 0.119 & 0.095 & 0.207 & -0.131 & 0.086 & 0.127 \\
\hline & Celeb: Ruler & 0.201 & 0.086 & 0.020 & -0.005 & 0.058 & 0.936 \\
\hline \multirow[b]{2}{*}{ Thin Celebs } & Celeb: Hips & 0.044 & 0.097 & 0.649 & -0.080 & 0.086 & 0.350 \\
\hline & Celeb: Ruler & 0.037 & 0.088 & 0.673 & 0.139 & 0.069 & 0.044 \\
\hline \multirow{2}{*}{ Normal Models } & Celeb: Hips & -0.047 & 0.102 & 0.645 & -0.020 & 0.095 & 0.836 \\
\hline & Celeb: Ruler & 0.070 & 0.100 & 0.485 & 0.021 & 0.067 & 0.754 \\
\hline \multirow{2}{*}{ Normal Celebs } & Celeb: Hips & 0.003 & 0.098 & 0.976 & -0.081 & 0.082 & 0.325 \\
\hline & Celeb: Ruler & -0.019 & 0.100 & 0.854 & 0.068 & 0.077 & 0.378 \\
\hline \multirow{2}{*}{ Heavy Models } & Celeb: Hips & 0.044 & 0.095 & 0.645 & -0.039 & 0.087 & 0.658 \\
\hline & Celeb: Ruler & 0.010 & 0.092 & 0.914 & 0.046 & 0.067 & 0.497 \\
\hline \multirow{2}{*}{ Heavy Celebs } & Celeb: Hips & -0.007 & 0.097 & 0.940 & -0.101 & 0.085 & 0.236 \\
\hline & Celeb: Ruler & 0.125 & 0.094 & 0.185 & 0.078 & 0.071 & 0.270 \\
\hline \multirow{2}{*}{ Thin Models } & Celeb: Bust & 0.012 & 0.159 & 0.939 & 0.074 & 0.156 & 0.638 \\
\hline & Celeb: Ruler & 0.203 & 0.065 & 0.002 & -0.103 & 0.044 & 0.020 \\
\hline \multirow{2}{*}{ Thin Celebs } & Celeb: Bust & -0.134 & 0.159 & 0.399 & 0.134 & 0.151 & 0.376 \\
\hline & Celeb: Ruler & 0.089 & 0.068 & 0.190 & 0.007 & 0.053 & 0.893 \\
\hline \multirow[b]{2}{*}{ Normal Models } & Celeb: Bust & -0.095 & 0.173 & 0.582 & 0.166 & 0.175 & 0.343 \\
\hline & Celeb: Ruler & 0.044 & 0.075 & 0.556 & -0.044 & 0.052 & 0.401 \\
\hline \multirow{2}{*}{ Normal Celebs } & Celeb: Bust & -0.033 & 0.159 & 0.835 & -0.052 & 0.139 & 0.707 \\
\hline & Celeb: Ruler & -0.001 & 0.076 & 0.985 & 0.010 & 0.058 & 0.858 \\
\hline \multirow{2}{*}{ Heavy Models } & Celeb: Bust & -0.010 & 0.158 & 0.950 & 0.010 & 0.149 & 0.945 \\
\hline & Celeb: Ruler & 0.036 & 0.070 & 0.607 & 0.004 & 0.053 & 0.936 \\
\hline \multirow{2}{*}{ Heavy Celebs } & Celeb: Bust & -0.170 & 0.160 & 0.287 & 0.118 & 0.154 & 0.444 \\
\hline & Celeb: Ruler & 0.126 & 0.071 & 0.078 & -0.042 & 0.053 & 0.427 \\
\hline
\end{tabular}

Note: Observations $=853$; Pseudo R-squared $=0.089 ;$ Log Likelihood $=-714.050 ;$ Model degrees of freedom $=40$; Chi-squared = 138.82 Marginal Effects (M.E.). Standard Error (SE). $p$ value ( $p$-Val.). 
Figure 3 plots the predicted probability of desired body shapes (hips and bust), conditional on the body shape of the respondent' favorite celebrity (hips or ruler), given that the respondent was assigned to view thin-sized models. Respondents were more likely to desire hips, regardless of whether they liked a celebrity with the hips $(\operatorname{Pr}=0.820, \mathrm{SE}=0.063, p<0.001)$ or ruler shape $(\operatorname{Pr}=0.678, \mathrm{SE}=0.055$, $p<0.001)$. However, favoring a celebrity with hips significantly increased the probability of desiring a silhouette with hips. There was no significant effect on the desire to have a bust, as this line almost remains flat across favorite celebrity body shapes (compare $\operatorname{Pr}=0.144, \mathrm{SE}=0.036, p<0.001$ for ruler celebrities with $\operatorname{Pr}=0.080, \mathrm{SE}=0.055, p<0.1$ for celebrities with hips).
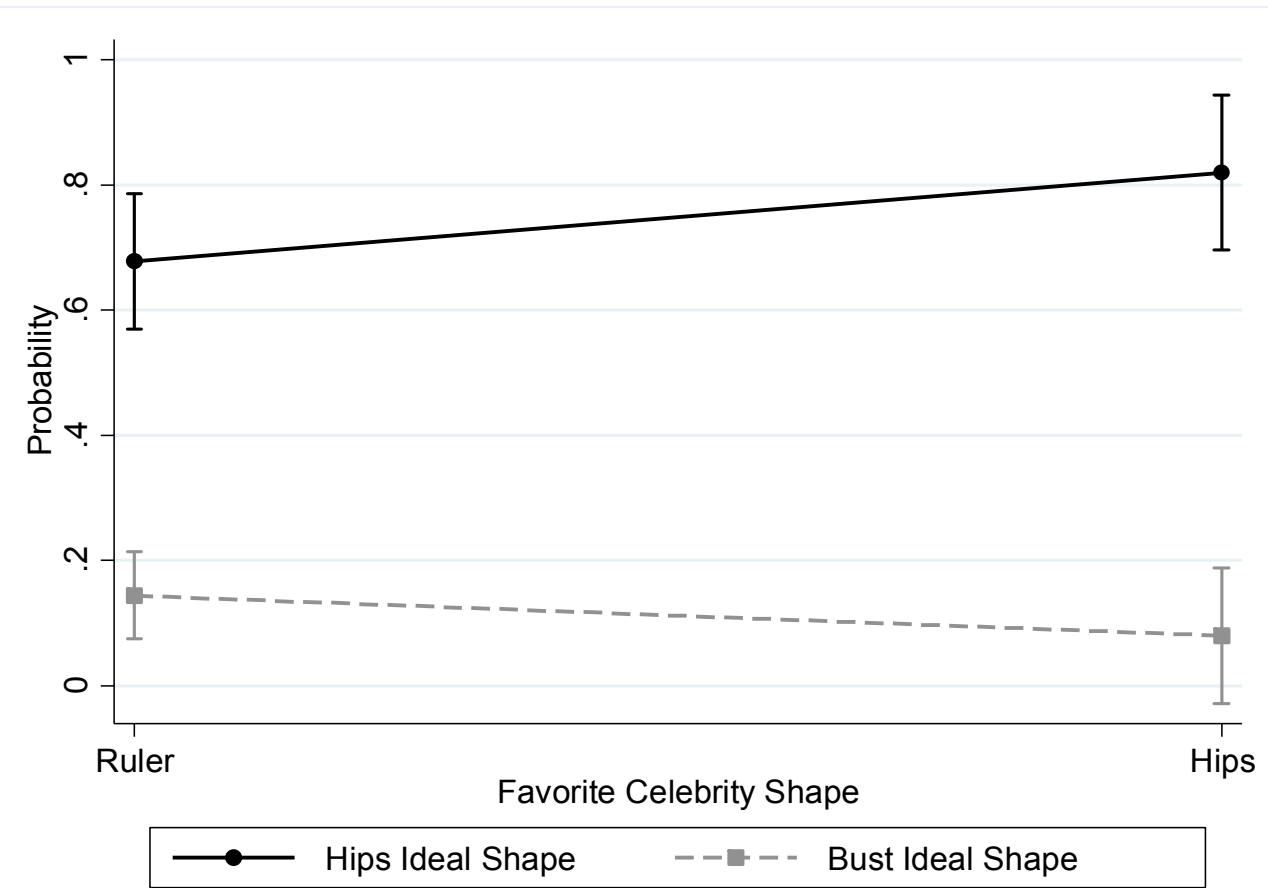

Figure 3. Predictive Margins for Thin models Treatment and Favorite Celebrity Body Shape (Hips versus Ruler).

Figure 4 plots the predictive margins for the interaction between the thin model treatment group and favoring celebrities with bust versus ruler. In this case, liking a busty celebrity significantly increased the probability of choosing the bust as the ideal shape (compare $\operatorname{Pr}=0.334, \mathrm{SE}=0.113$, $p<0.001$ for busty celebrities with $\operatorname{Pr}=0.052, \mathrm{SE}=0.023, p<0.001$ for ruler celebrities), while it decreased the probability of choosing the hips as the ideal body shape ( $\operatorname{Pr}=0.541, \mathrm{SE}=0.112, p<0.001$ for busty celebrities with $\operatorname{Pr}=0.803, \mathrm{SE}=0.041, p<0.001$ for ruler celebrities).

Consistent results in terms of both significance and magnitude were obtained for all sensitivity analyses (data not shown). This gives us confidence that the results obtained here were robust irrespective of the way the dependent and independent variables were operationalized. 


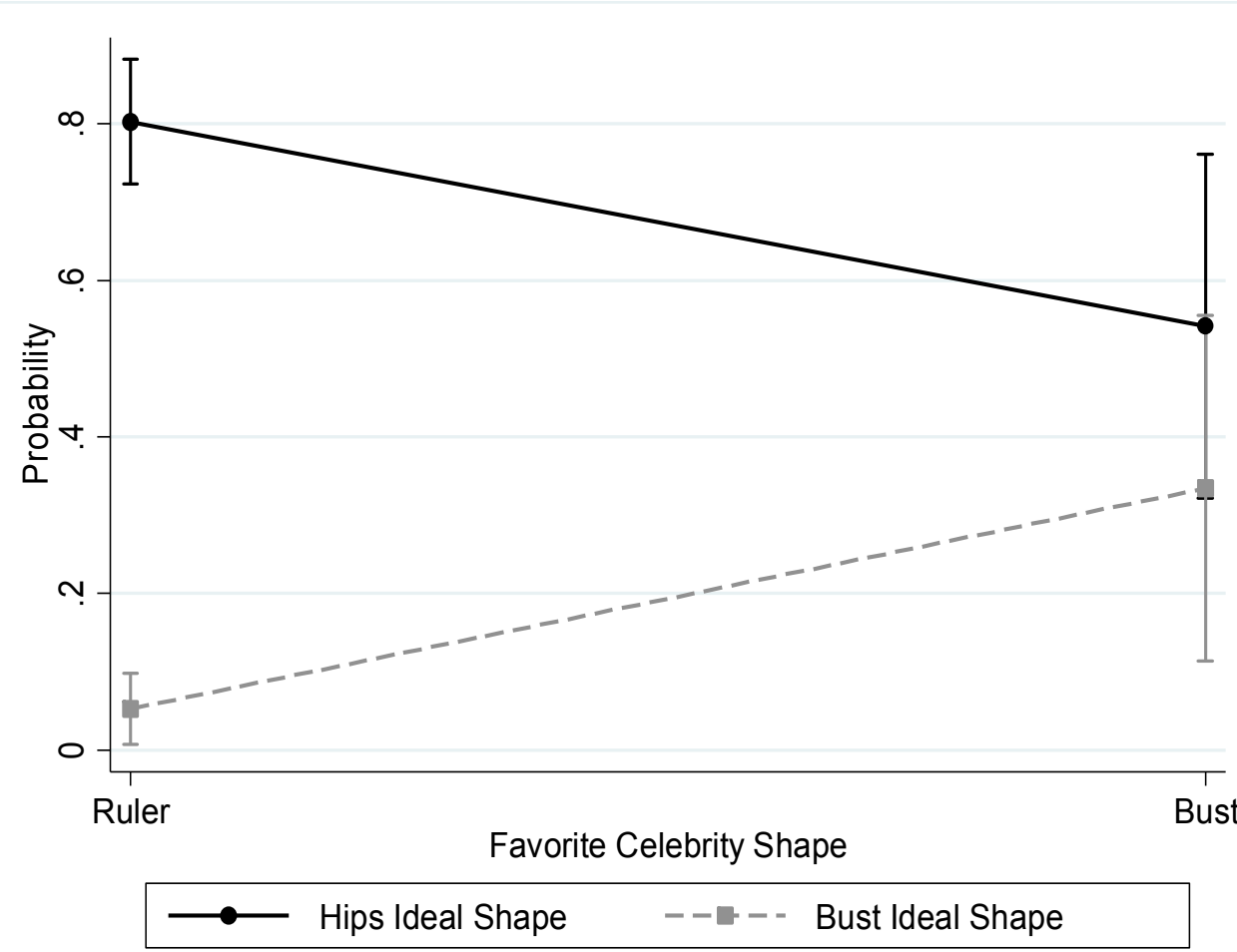

Figure 4. Predictive Margins for Thin models Treatment and Favorite Celebrity Body Shape (Bust versus Ruler).

\section{Discussion}

Many studies attribute the rising prevalence of BID in non-Western countries including the Middle East to the globalization of Western media (Nasser 1986; Swami et al. 2010). Among Arab women, this means shifting body size ideals toward thinness and away from the historical cultural ideals of a heavier body size and plumper body shape (Nasser 1988). To our knowledge this is the first experimental study that closely examined the effects of acute exposure to Western media images and tested their presumed effect on Arab women's desired body size and body shape ideals. Using a large representative sample of Arab university female students living in a rapidly developing country with a conservative Islamic society as a backdrop, a survey experiment was designed to test the primary hypothesis that exposure to images of thin models or celebrities promotes a thinner body ideal compared to neutral images.

\subsection{Experimental Effects on BID in Body Size}

Contrary to our primary hypothesis, we found that Arab females who viewed thin images of celebrities or models were not significantly more likely to desire thinner body size relative to those who viewed neutral images. Therefore, our study provides no evidence in support of the influence of Western media icons on the desire for thinness in this population. This can be contrasted with other experimental studies in Western countries that observed the opposite to be true (Groesz et al. 2002; Levine and Murnen 2009).

\subsection{Moderation of Experimental Effects on BID in Body Size by Favorite Celebrity Body Size}

On the contrary to our secondary hypothesis of moderation of treatment effects on desire for thinness by favorite celebrity's body size, images of average-sized (but not thin) celebrities induced the desire for thinness among those who already favored thin over heavy celebrities. In the cultural 
context of our study, the finding that only average-sized celebrities produced the effects expected of thin celebrities in Western countries could suggest influence of cultural norms with regards to body size on perception of portrayed body images of Western media icons. In other words, only images that portray culturally sanctioned levels of thinness would elicit the desire for a thinner look among women in this non-Western setting. This is to say that even though respondents may favor thin Western celebrities and are exposed to images of thin celebrities; this does not necessarily mean that they will idealize thinner body size. It appears that cultural stereotypes about the 'appropriate' level of thinness may be an important variable in this context. This explanation is consistent with a large body of literature that supports the role of culture and social conditioning by family or peers on the internalization of thin appearance ideals portrayed by the media (Stanford and Mccabe 2002; Thompson and Stice 2001).

Equally surprising, and contrary to what we predicted, the effects of exposure to thin images of celebrities on the desired change in body size were not exclusively in the direction of a thinner look, but also in the direction of a heavier look. This was especially true for respondents who favored thin celebrities and were also exposed to thin celebrities. This suggests that perception of body size is inextricably linked to body shape, emphasizing the need to consider both body size and body shape in studies of BID. In fact, some of the more recent literature research supports the notion of the curvy-thin as the new thin body ideal among both white women (Webb et al. 2013) and women of other ethnicities (Talleyrand et al. 2016; Viladrich et al. 2009). Meanwhile, cultures with traditional sex roles tend to have preferences for body shapes associated with fertility, especially the hourglass body shape (Furnham and Nordling 1998; Singh 2006). Thus young females from more traditional cultures may idealize body shapes that are more curvaceous and conducive to their traditional roles.

\subsection{Experimental Effects on BID in Body Shape}

Preferences for the ideal body shape in our sample were generally more in favor of curvaceous body shapes with hips including the hourglass (shape 5) and the inverted triangle (shape 2). In this respect, about half of the women in our sample selected an ideal body shape that matched the expectations of the mainstream Arab culture. Since women in Arab culture attain higher social status through motherhood, larger hips were perhaps perceived as a symbol of power in addition to maternity and nurturance (Hamady 1960). Idealizing body shapes that are less curvaceous and thus less conducive to a woman's traditional role as a mother may be viewed negatively in this culture. This may also explain why fewer women desired the busty figure as their ideal body shape even though this was their favorite celebrity shape.

To the best of our knowledge, there are no studies that examined the impact of experimental exposure to images of fashion and media icons on body shape ideals in women in general and in Arab women in particular. Thus, our study addresses an important gap in the literature. Our findings suggest that exposure to images of thin models (without full body figures in hips or busts) significantly increases the desire for fullness in participants' ideal body shape. In particular, women acutely exposed to images of thin models were significantly more likely to desire a body shape with hips. Moreover, participants' favorite celebrity body shape was also an independent predictor of the same body shape ideal in the participants. Additionally, desiring a heavier silhouette as an ideal body size showed a strong positive association with selecting hips (inverted triangle) as the ideal body shape, but weaker and non-significant association with the bust as the ideal body shape.

\subsection{Moderation of Experimental Effects on BID in Body Shape by Favorite Celebrity Body Shape}

Our tests for interactions between the treatment groups and favorite celebrity body shape on participants' body shape ideals revealed some interesting findings especially for the thin model treatment. Participants who favored celebrities with hips and viewed images of thin models were significantly more likely to idealize hips over bust in comparison to those who viewed neutral images. In contrast, participants who favored celebrities with busty figures and viewed images of thin models 
were not more likely to select bust over hips as their ideal body shape. Similarly, participants who favored celebrities with ruler-like or tubular body shapes were significantly more likely to idealize hips rather than tubular body shapes over bust in comparison to those who viewed neutral images. Based on these findings, it would appear that viewing images of thin models acutely induced the desire for a curvaceous body shapes especially in hips among those who favored celebrities with hips and those who did not. Once again, our results support the importance of sociocultural factors in driving body shape ideals towards culturally sanctioned norms especially in cases where body shapes of favorite Western celebrities are not considered by the main stream culture as ideal (i.e., without hips or tubular). This is to say that when exposed to images of thin models, participants who may otherwise favor Western celebrities with busty or ruler figures will still be more likely to choose curvaceous figures with culturally sanctioned features as their ideal body shape. In fact, it has been suggested that women living in a culture with traditional sex roles tend to have preferences for body shapes that are deemed as attractive in the traditional sense especially the hourglass body shape (Furnham and Nordling 1998; Maier and Lavrakas 1984; Singh 2006).

\subsection{Limitations and Future Studies}

A limitation of our study relates to the mode of administration of our experiment. Online surveys are relatively inexpensive, and are less likely to evoke social desirability response bias and interviewer effects, making it easier for respondents to disclose sensitive information (Kreuter et al. 2008). Yet many experiments are conducted in the more controlled context of a face-to-face interview, which reduces noise in the results. Relatedly, the study could have benefitted from longer measures that assess respondent's current and idealized body features. The decision to use the brief measures for assessing BID in body-related size and shape was based on expediency; the measures needed to be administered online, and within the brief time allocation of an online survey. In terms of our choice of stimulus material, the dimensions of the featured bodies in the images selected may have been disguised by the clothing. In order to observe cultural customs of decorum in female attire, we were not able to show images depicting models in bathing suits or underwear. Another problem with using real life images is that the bust, hip, and waist widths tend to be affected by the body position of the featured model or celebrity. We tried to minimize this variation by selecting images with the same forward facing pose whenever possible. It is also unclear whether our findings would generalize to females of lower educational status or females of the same age or of different ages in the general population.

\section{Conclusions}

The thin ideal is increasingly a transcultural phenomenon. Arab women constitute a high-risk group for BID due to shifts in traditional roles, changes in diet, lifestyle, and increased exposure to thin images through social media outlets. To date, experimental studies on the impact of Western models and celebrities on women's body ideals in non-Western settings are scarce. The present study fills this lacuna by examining body size and shape ideals using an experimental design. We find the desire for a thinner body occurs only under specific conditions, such as among those who already favor thin celebrities and view images of celebrities (but not models), and then only for celebrities within a culturally acceptable range of thinness. Thus, the results showed a more nuanced picture than that predicted by past theories. Future research should account for how culturally shaped preferences influence body ideals. Desiring a heavier look may also be related to the current trends in which celebrities like Jennifer Lopez and the Kardashians are reviving the curvaceous silhouette as the ideal body shape among younger women. In fact, our findings with respect to body shape corroborate this by showing that respondents were driven to desire fuller body shapes with hips upon viewing images of thin models that do not have this feature, particularly when their favorite celebrity has a fuller body shape with either hips or a bust. Accordingly, our findings highlight important nuances in the influence of culture and media on body-image perception among younger women in non-Western cultures. 
Supplementary Materials: The following are available online at http:/ /www.mdpi.com/2076-0760/7/9/142/s1, Figure S1: Images used for the thin-sized celebrity treatment group, Figure S2: Images used for the average-sized celebrity treatment group, Figure S3: Images used for the heavy sized celebrity treatment group, Figure S4: Images used for the thin-sized model treatment group, Figure S5: Images used for the average-sized model treatment group, Figure S6: Images used for the heavy-sized model treatment group, Figure S7: Images used for the Control group.

Author Contributions: All authors jointly contributed to the design of the study. S.M.K. and B.S. contributed to the analysis of data. All authors contributed to the writing of the manuscript. All authors have read and approved the final manuscript.

Funding: This research received no external funding.

Acknowledgments: The Social and Economic Survey Research Institute at Qatar University made this study possible. The statements made herein are solely the responsibility of the authors.

Conflicts of Interest: The authors declare no conflict of interest.

\section{Appendix A}

\section{Section 1. BODY SIZE DISSATISFACTION QUESTIONS}

The following are questions specific to how you perceive your own body.

\section{Current Body Size}

Which number from the below image do you feel is closest to your body at present?

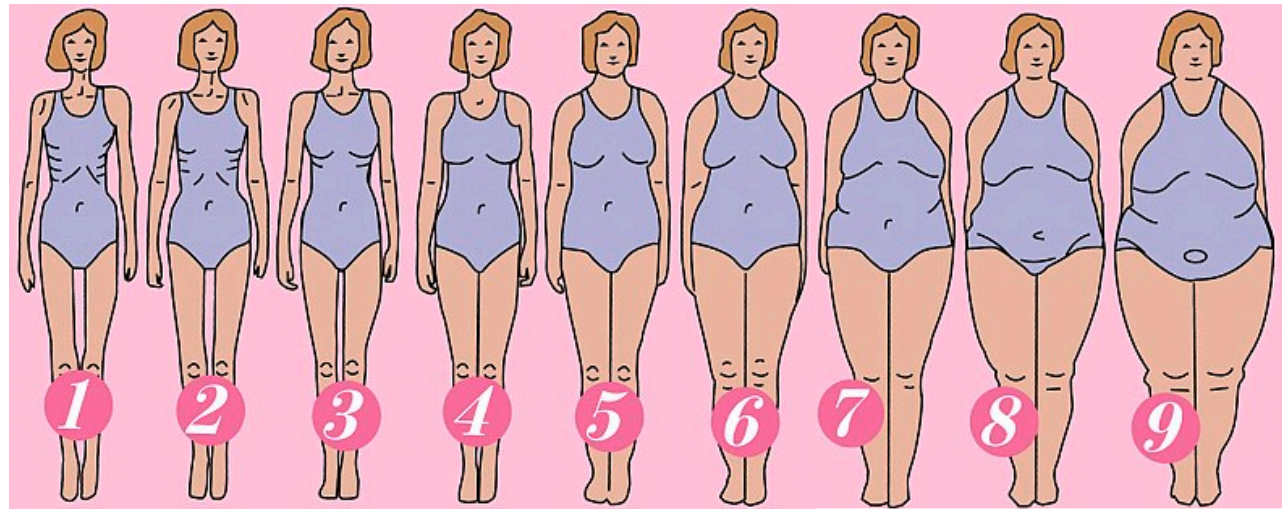

Figure A1. Current Body Size.

\section{Ideal Body Size}

Which number from the below image would you most like to look like?

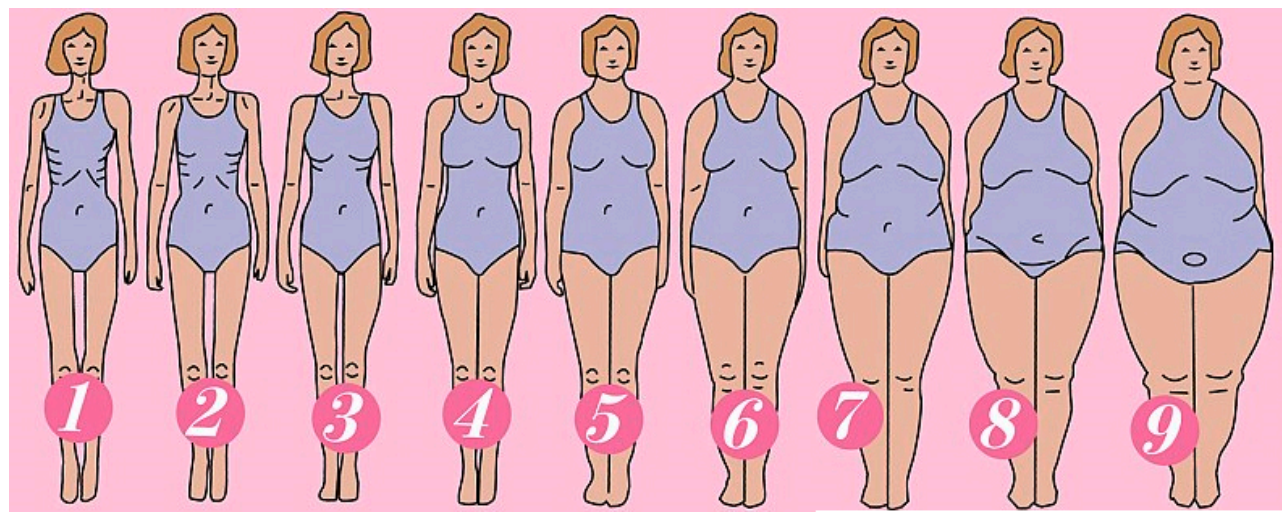

Figure A2. Current Body Size. 


\section{Section 2. BODY SHAPE DISSATISFACTION QUESTIONS}

\section{Current Body Shape}

The following images include 5 different body shapes, numbered 1 to 5 .
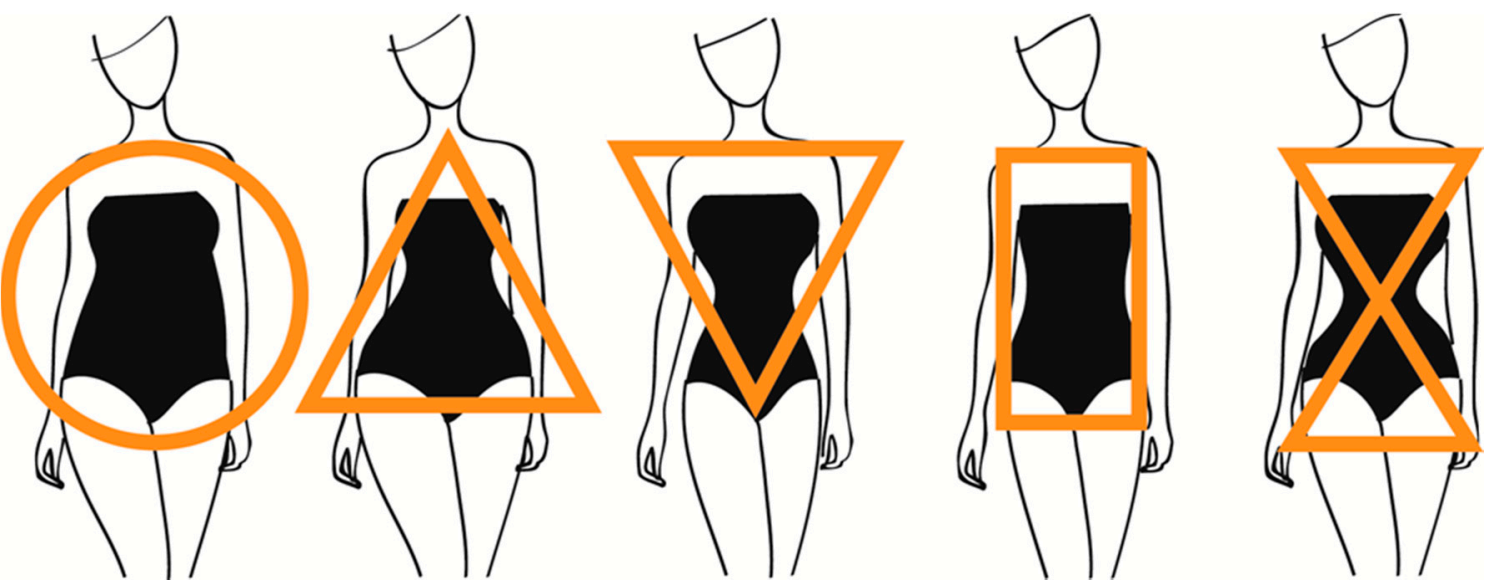

Figure A3. Current Body Shape.

Please select the body shape that in your opinion most corresponds with your body shape now?

\section{Ideal Body Shape}

The following images include 5 different body shapes, numbered 1 to 5 .
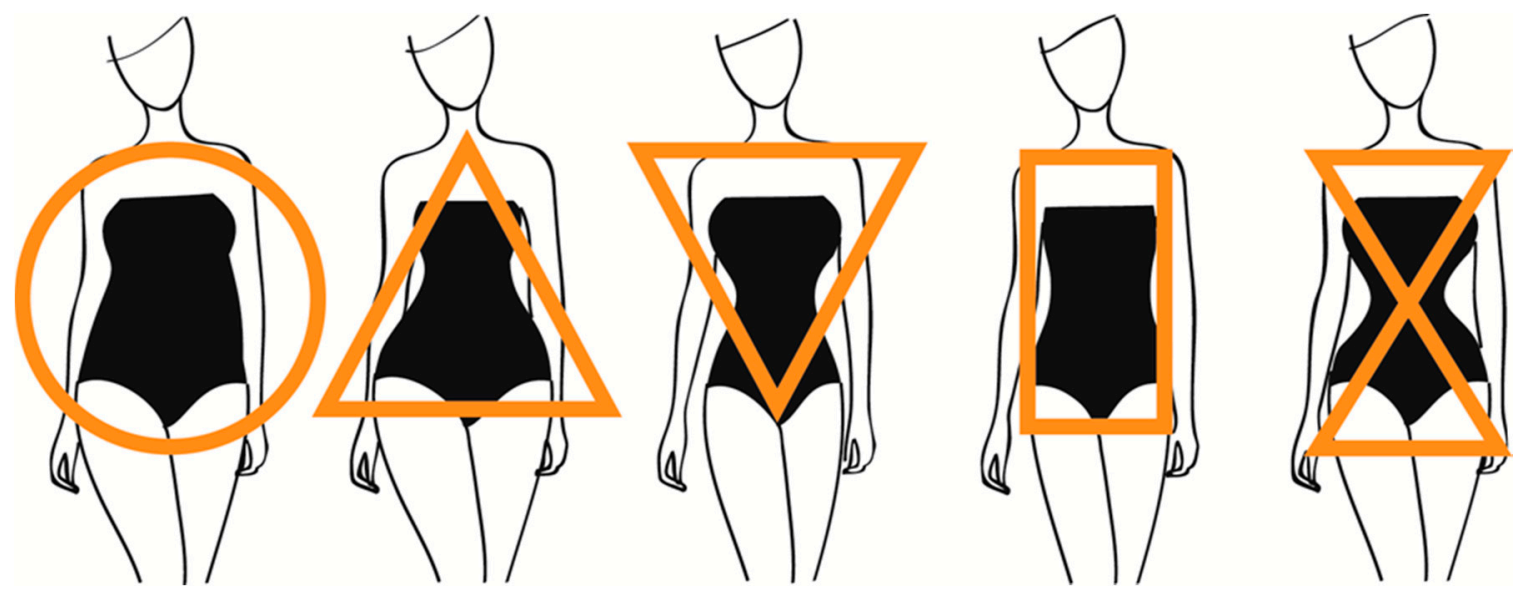

Figure A4. Ideal Body Shape.

Please select the body shape that in your opinion most corresponds with your ideal body shape?

\section{Section 3. DEMOGRAPHIC AND OTHER QUESTIONS}

\section{Marriage Status}

What is your current marital status?

1. Married

2. Separated

3. Divorced

4. Widowed 
5. Never married

6. I do not wish to disclose

\section{Socioeconomic Status}

How would you describe your family's economic status?

1. Poor

2. Financially challenged

3. Financially stable

4. Financially comfortable

5. Wealthy

9998. DON'T KNOW

9999. REFUSED

\section{Mother Education}

What is the highest level of education completed by your mother?

1. Less than high school diploma

2. High school diploma

3. College degree

4. Undergraduate

5. Graduate degree

6. Post-graduate degree of Post-doctoral degree

9998. DON'T KNOW

9999. REFUSED

\section{Father Education}

What is the highest level of education completed by your mother?

1. Less than high school diploma

2. High school diploma

3. College degree

4. Undergraduate

5. Graduate degree

6. Post-graduate degree of Post-doctoral degree

9998. DON'T KNOW

9999. REFUSED

Age

What is your age (years)? Please put 0 if you do NOT wish to disclose

\section{BMI}

What is your current weight $(\mathrm{kg})$ ?

What is your height $(\mathrm{cm})$ ?

\section{Section 4. Celebrity Liking and Recognition Questions}




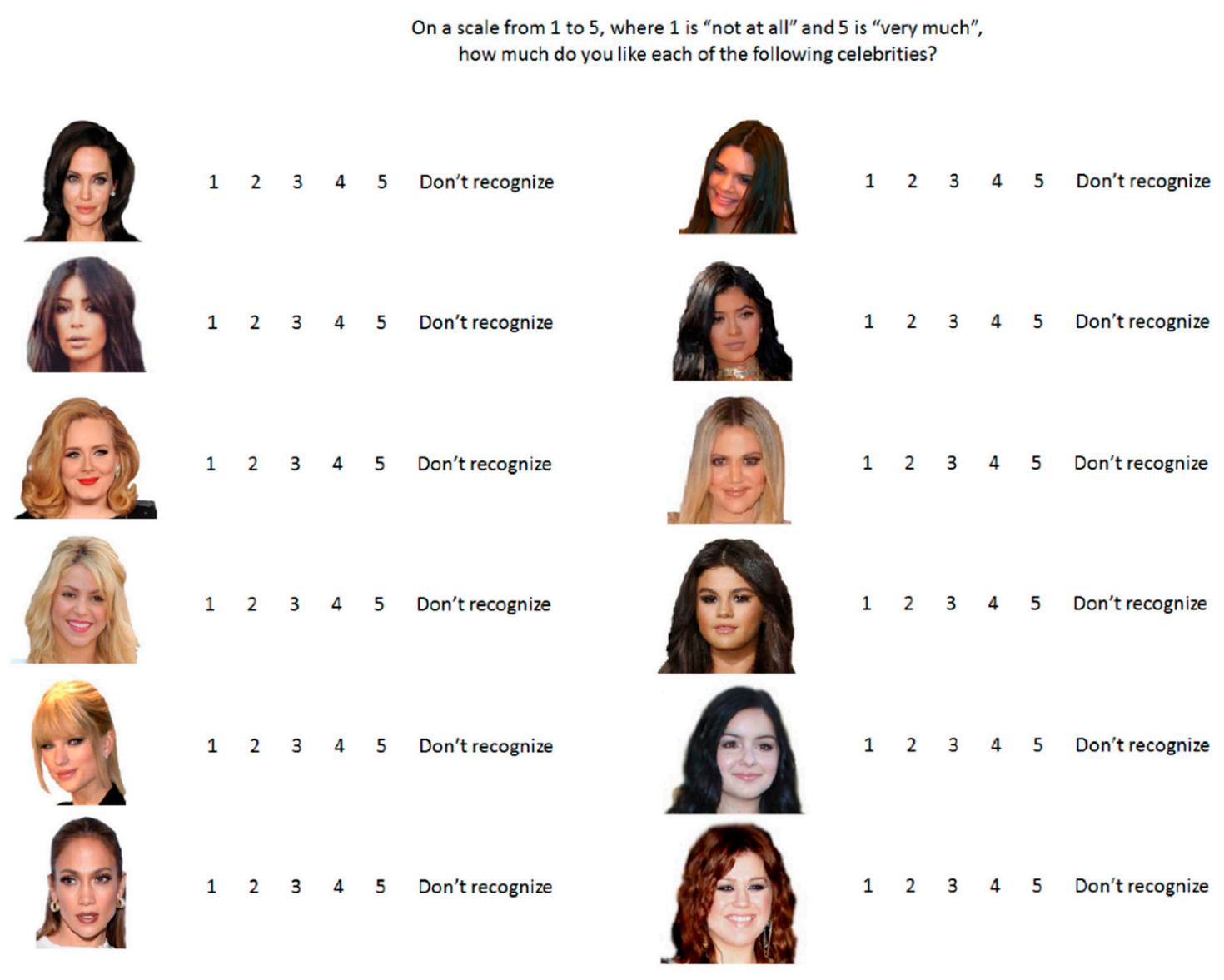

Figure A5. Celebrity Liking and Recognition.

\section{References}

Ali, Faleh Mohamed Hussain, Zlatko Nikoloski, Husein Reka, Orsida Gjebrea, and Elias Mossialos. 2014. The diabetes-obesity-hypertension nexus in Qatar: Evidence from the World Health Survey. Population Health Metrics 12: 18. [CrossRef] [PubMed]

Babar, Zahra. 2015. Population, Power, and Distributional Politics in Qatar. Journal of Arabian Studies 5: 138-55. [CrossRef]

Baptista, Kaitlyn. 2011. A Cross-National Examination of Body Image and Media Exposure Comparisons between Jordanian and American Women. Undergraduate Review 7: 14-21.

Boyatzis, Chris J., and Katherine B. Quinlan. 2008. Women's Body Image, Disordered Eating, and Religion: A Critical Review of the Literature. Leiden: Brill. Available online: http:/ / booksandjournals.brillonline.com/content/ books/10.1163/ej.9789004166462.i-299.61 (accessed on 21 May 2017).

Brechan, Inge, and Ingela Lundin Kvalem. 2015. Relationship between body dissatisfaction and disordered eating: Mediating role of self-esteem and depression. Eating Behaviors 17: 49-58. [CrossRef] [PubMed]

Brown, Amy, and Helga Dittmar. 2005. Think “Thin” and Feel Bad: The Role of Appearance Schema Activation, Attention Level, and Thin-Ideal Internalization for Young Women's Responses to Ultra-Thin Media Ideals. Journal of Social and Clinical Psychology 24: 1088-113. [CrossRef]

Brown, Zoe, and Marika Tiggemann. 2016. Attractive celebrity and peer images on Instagram: Effect on women's mood and body image. Body Image 19: 37-43. [CrossRef] [PubMed]

Cattarin, Jill A., J. Kevin Thompson, Carmen Thomas, and Robyn Williams. 2000. Body image, mood, and televised images of attractiveness: The role of social comparison. Journal of Social and Clinical Psychology 19: 220-39. [CrossRef] 
Chang, Fong-Ching, Ching-Mei Lee, Ping-Hung Chen, Chiung-Hui Chiu, Yun-Chieh Pan, and Tzu-Fu Huang. 2013. Association of thin-ideal media exposure, body dissatisfaction and disordered eating behaviors among adolescents in Taiwan. Eating Behaviors 14: 382-85. [CrossRef] [PubMed]

Cooper, Peter J., and Christopher G. Fairburn. 1993. Confusion over the core psychopathology of bulimia nervosa. International Journal of Eating Disorders 13: 385-89. [CrossRef]

Dennis, Everette E., Justin D. Martin, Robb Wood, and Marium Saeed. 2016. Media Use in the Middle East 2016: A Six-Nation Survey. Doha: Northwestern University in Qatar, Doha Film Institute, Harris Pol. Available online: https: / / www.qatar.northwestern.edu/docs/publications/research-media-use/2016-middle-eastmedia-use-report.pdf (accessed on 9 March 2017).

Dittmar, Helga. 2009. How Do "Body Perfect" Ideals in the Media Have a Negative Impact on Body Image and Behaviors? Factors and Processes Related to Self and Identity. Journal of Social and Clinical Psychology 28: 1-8. [CrossRef]

Dittmar, Helga, Emma Halliwell, and Emma Stirling. 2009. Understanding the Impact of Thin Media Models on Women's Body-Focused Affect: The Roles of Thin-Ideal Internalization and Weight-Related Self-Discrepancy Activation in Experimental Exposure Effects. Journal of Social and Clinical Psychology 28: 43-72. [CrossRef]

Dittmar, Helga, and Sarah Howard. 2004. Thin-Ideal Internalization and Social Comparison Tendency as Moderators of Media Models' Impact on Women's Body-Focused Anxiety. Journal of Social and Clinical Psychology 23: 768-91. [CrossRef]

Dunkel, Trisha M., Denise Davidson, and Shaji Qurashi. 2010. Body satisfaction and pressure to be thin in younger and older Muslim and non-Muslim women: The role of Western and non-Western dress preferences. Body Image 7: 56-65. [CrossRef] [PubMed]

Eapen, Valsamma, Abdel Azim Mabrouk, and Salem Bin-Othman. 2006. Disordered eating attitudes and symptomatology among adolescent girls in the United Arab Emirates. Eating Behaviors 7: 53-60. [CrossRef] [PubMed]

Festinger, Leon. 1954. A Theory of Social Comparison Processes. Human Relations 7: 117-40. [CrossRef]

Ford, Kathryn A., Bridget M. Dolan, and Chris Evans. 1990. Cultural factors in the eating disorders: A study of body shape preferences of Arab students. Journal of Psychosomatic Research 34: 501-7. [CrossRef]

Furnham, Adrian, and Naznin Alibhai. 1983. Cross-cultural differences in the perception of female body shapes. Psychological Medicine 13: 829-37. [CrossRef] [PubMed]

Furnham, Adrian, and Peter Baguma. 1994. Cross-cultural differences in the evaluation of male and female body shapes. The International Journal of Eating Disorders 15: 81-89. [CrossRef]

Furnham, Adrian, and R. Nordling. 1998. Cross-cultural differences in preferences for specific male and female body shapes. Personality and Individual Differences 25: 635-48. [CrossRef]

Garner, David M., Paul E. Garfinkel, Donald Schwartz, and Michael Thompson. 1980. Cultural expectations of thinness in women. Psychological Reports 47: 483-91. [CrossRef] [PubMed]

Grabe, Shelly, L. Monique Ward, and Janet Shibley Hyde. 2008. The role of the media in body image concerns among women: A meta-analysis of experimental and correlational studies. Psychological Bulletin 134: 460-76. [CrossRef] [PubMed]

Groesz, Lisa M., Michael P. Levine, and Sarah K. Murnen. 2002. The effect of experimental presentation of thin media images on body satisfaction: A meta-analytic review. International Journal of Eating Disorders 31: 1-16. [CrossRef] [PubMed]

Grogan, Sarah. 2006. Body image and health: Contemporary perspectives. Journal of Health Psychology 11: 523-30. [CrossRef] [PubMed]

Halliwell, Emma, and Helga Dittmar. 2005. The role of self-improvement and self-evaluation motives in social comparisons with idealised female bodies in the media. Body Image 2: 249-61. [CrossRef] [PubMed]

Hamady, Sania. 1960. Temperament and Character of the Arabs. Boston: Twayne Publications.

Harrison, Kristen. 1997. Does interpersonal attraction to thin media personalities promote eating disorders? Journal of Broadcasting E Electronic Media 41: 478-500. [CrossRef]

Hausman, Jerry, and Daniel McFadden. 1984. Specification tests for the multinomial logit model. Econometrica: Journal of the Econometric Society 52: 1219-40. [CrossRef]

Irving, Lori M. 1990. Mirror Images: Effects of the Standard of Beauty on the Self- and Body-Esteem of Women Exhibiting Varying Levels of Bulimic Symptoms. Journal of Social and Clinical Psychology 9: 230-42. [CrossRef] 
Kreuter, Frauke, Stanley Presser, and Roger Tourangeau. 2008. Social Desirability Bias in CATI, IVR, and Web SurveysThe Effects of Mode and Question Sensitivity. Public Opinion Quarterly 72: 847-65. [CrossRef]

Levine, Michael P., and Sarah K. Murnen. 2009. “Everybody knows that mass media are/are not [pick one] a cause of eating disorders": A critical review of evidence for a causal link between media, negative body image, and disordered eating in females. Journal of Social and Clinical Psychology 28: 9-42. [CrossRef]

Madanat, Hala N., Ralph B. Brown, and Steven R. Hawks. 2007. The impact of body mass index and Western advertising and media on eating style, body image and nutrition transition among Jordanian women. Public Health Nutrition 10: 1039-46. [CrossRef] [PubMed]

Madanat, Hala, Steven R. Hawks, and Heidi N. Angeles. 2010. Obesity and Body Size Preferences of Jordanian Women. Health Education \& Behavior 38: 91-98. [CrossRef]

Mahoney, Annette, Robert A. Carels, Kenneth I. Pargament, Amy Wachholtz, Laura Edwards Leeper, Mary Kaplar, and Robin Frutchey. 2005. RESEARCH: "The Sanctification of the Body and Behavioral Health Patterns of College Students". The International Journal for the Psychology of Religion 15: 221-38. [CrossRef]

Maier, Richard A., and Paul J. Lavrakas. 1984. Attitudes toward women, personality rigidity, and idealized physique preferences in males. Sex Roles 11: 425-33. [CrossRef]

McCabe, Marita P., Matthew Fuller-Tyszkiewicz, David Mellor, Lina Ricciardelli, Helen Skouteris, and Alex Mussap. 2012. Body satisfaction among adolescents in eight different countries. Journal of Health Psychology 17: 693-701. [CrossRef] [PubMed]

McLean, Siân A. 2013. Body dissatisfaction and obesity: Consequences and implications for intervention. Obesity Research \& Clinical Practice 7: e10. [CrossRef]

Morokoff, William J., and Russel E. Caflisch. 1995. Quasi-monte carlo integration. Journal of Computational Physics 122: 218-30. [CrossRef]

Mousa, Tamara Y., Rima H. Mashal, Hayder A. Al-Domi, and Musa A. Jibril. 2010. Body image dissatisfaction among adolescent schoolgirls in Jordan. Body Image 7: 46-50. [CrossRef] [PubMed]

Musaiger, Abdulrahman. 2015. Body weight concern among female university students in five Arab countries-A preliminary cross-cultural study. Annals of Agricultural and Environmental Medicine 22: 349-52. [CrossRef] [PubMed]

Nasser, Mervat. 1986. Comparative study of the prevalence of abnormal eating attitudes among Arab female students of both London and Cairo universities. Psychological Medicine 16: 621-25. [CrossRef] [PubMed]

Nasser, Mervat. 1988. Culture and weight consciousness. Journal of Psychosomatic Research 32: 573-77. [CrossRef]

Nasser, Mervat. 1997. Culture and Weight Consciousness. Abingdon: Routledge.

Omori, Mika, Yoko Yamazaki, Noriko Aizawa, and Piyanjali de Zoysa. 2016. Thin-ideal internalization and body dissatisfaction in Sri Lankan adolescents. Journal of Health Psychology 22: 1830-40. [CrossRef] [PubMed]

Shorter, Louise, Stephen L. Brown, Stephanie J. Quinton, and Louise Hinton. 2008. Relationships between Body-Shape Discrepancies with Favored Celebrities and Disordered Eating in Young Women. Journal of Applied Social Psychology 38: 1364-77. [CrossRef]

Singh, Devendra. 2006. Universal allure of the hourglass figure: An evolutionary theory of female physical attractiveness. Clinics in Plastic Surgery 33: 359-70. [CrossRef] [PubMed]

Singh, Devendra, and Robert K. Young. 1995. Body weight, waist-to-hip ratio, breasts, and hips: Role in judgments of female attractiveness and desirability for relationships. Ethology and Sociobiology 16: 483-507. [CrossRef]

Singh, Devendra. 1994. Ideal female body shape: Role of body weight and waist-to-hip ratio. International Journal of Eating Disorders 16: 283-88. [CrossRef]

Stanford, Jacqueline N., and Marita P. Mccabe. 2002. Body Image Ideal among Males and Females: Sociocultural Influences and Focus on Different Body Parts. Journal of Health Psychology 7: 675-84. [CrossRef] [PubMed]

StataCorp. 2013. Stata Statistical Software: Release 13 (Version 13). College Station: StataCorp LP. Available online: http:/ / www.stata.com/support/faqs/resources/citing-software-documentation-faqs/ (accessed on 6 October 2017).

Stunkard, Albert J. 1983. Use of the Danish Adoption Register for the study of obesity and thinness. Research Publications-Association for Research in Nervous and Mental Disease 60: 115-20. [PubMed]

Swami, Viren, David A. Frederick, Toivo Aavik, Lidia Alcalay, Jüri Allik, Donna Anderson, Sonny Andrianto, Arvind Arora, Åke Brännström, John Cunningham, and et al. 2010. The Attractive Female Body Weight and Female Body Dissatisfaction in 26 Countries Across 10 World Regions: Results of the International Body Project I. Personality and Social Psychology Bulletin 36: 309-25. [CrossRef] [PubMed] 
Swami, Viren, Rosanne Taylor, and Christine Carvalho. 2011a. Body dissatisfaction assessed by the Photographic Figure Rating Scale is associated with sociocultural, personality, and media influences. Scandinavian Journal of Psychology 52: 57-63. [CrossRef] [PubMed]

Swami, Viren, Rosanne Taylor, and Christine Carvalho. 2011b. Body dissatisfaction assessed by the Photographic Figure Rating Scale is associated with sociocultural, personality, and media influences. Scandinavian Journal of Psychology 52: 57-63. [CrossRef] [PubMed]

Talleyrand, Regine M., Amanda D. Gordon, Jewelle V. Daquin, and Adanna J. Johnson. 2016. Expanding Our Understanding of Eating Practices, Body Image, and Appearance in African American Women: A Qualitative Study. Journal of Black Psychology 43: 464-92. [CrossRef]

Thompson, J. Kevin, and Eric Stice. 2001. Thin-Ideal Internalization: Mounting Evidence for a New Risk Factor for Body-Image Disturbance and Eating Pathology. Current Directions in Psychological Science 10: 181-83. [CrossRef]

Tiggemann, Marika, and Belinda McGill. 2004. The Role of Social Comparison in the Effect of Magazine Advertisements on Women's Mood and Body Dissatisfaction. Journal of Social and Clinical Psychology 23: $23-44$. [CrossRef]

Tiggemann, Marika, and Janet Polivy. 2010. Upward and Downward: Social Comparison Processing of Thin Idealized Media Images. Psychology of Women Quarterly 34: 356-64. [CrossRef]

Tiggemann, Marika, Janet Polivy, and Duane Hargreaves. 2009. The processing of thin ideals in fashion magazines: A source of social comparison or fantasy? Journal of Social and Clinical Psychology 28: 73-93. [CrossRef]

Vague, Jean. 1956. The degree of masculine differentiation of obesities: A factor determining predisposition to diabetes, atherosclerosis, gout, and uric calculous disease. The American Journal of Clinical Nutrition 4: 20-34. [CrossRef] [PubMed]

Viladrich, Anahí, Ming-Chin Yeh, Nancy Bruning, and Rachael Weiss. 2009. “Do Real Women Have Curves?" Paradoxical body images among Latinas in New York City. Journal of Immigrant and Minority Health 11: $20-28$. [CrossRef] [PubMed]

Want, Stephen C. 2009. Meta-analytic moderators of experimental exposure to media portrayals of women on female appearance satisfaction: Social comparisons as automatic processes. Body Image 6: 257-69. [CrossRef] [PubMed]

Webb, Jennifer B., Jan Warren-Findlow, Ying-Yi Chou, and Lauren Adams. 2013. Do you see what I see?: An exploration of inter-ethnic ideal body size comparisons among college women. Body Image 10: 369-79. [CrossRef] [PubMed]

(C) 2018 by the authors. Licensee MDPI, Basel, Switzerland. This article is an open access article distributed under the terms and conditions of the Creative Commons Attribution (CC BY) license (http://creativecommons.org/licenses/by/4.0/). 